\title{
The co-chaperone Fkbp5 shapes the acute stress response in the paraventricular nucleus of the hypothalamus
}

\author{
Alexander S. Häus ${ }^{1}{ }^{*}$, Jakob Hartmann ${ }^{2}$, Max L. Pöhlmann ${ }^{1}$, Lea M. Brix ${ }^{1,3}$, Juan-Pablo Lopez ${ }^{4}$, Elena Brivio ${ }^{3,4}$, Clara \\ Engelhardt ${ }^{1}$, Simone Roeh ${ }^{5}$, Lisa Rudolph ${ }^{4}$, Rainer Stoffel ${ }^{4}$, Kathrin Hafner ${ }^{5}$, Hannah M. Goss ${ }^{6}$, Johannes M.H.M. Reul ${ }^{6}$, \\ Jan M. Deussing ${ }^{7}$, Kerry J. Ressler ${ }^{2}$, Nils C. Gassen ${ }^{4,8}$, Alon Chen $^{3,9}$ and Mathias V. Schmidt ${ }^{1 *}$
}

${ }^{1}$ Research Group Neurobiology of Stress Resilience, Max Planck Institute of Psychiatry, 80804 Munich, Germany

${ }^{2}$ Department of Psychiatry, Harvard Medical School, McLean Hospital, Belmont, MA, USA

${ }^{3}$ International Max Planck Research School for Translational Psychiatry (IMPRS-TP), Kraepelinstr. 2-10, 80804 Munich, Germany

${ }^{4}$ Department of Stress Neurobiology and Neurogenetics, Max Planck Institute of Psychiatry, 80804 Munich, Germany

${ }^{5}$ Department of Translational Research in Psychiatry, Max Planck Institute of Psychiatry, 80804 Munich, Germany

${ }^{6}$ Neuro-Epigenetics Research Group, Bristol Medical School, University of Bristol, Bristol BS1 3NY, United Kingdom

${ }^{7}$ Research Group Molecular Neurogenetics, Max Planck Institute of Psychiatry, 80804 Munich, Germany

${ }^{8}$ Department of Psychiatry and Psychotherapy, Bonn Clinical Center, University of Bonn, 53127 Bonn, Germany

${ }^{9}$ Weizmann Institute of Science, Department of Neurobiology, Rehovot, Israel

*Correspondence should be addressed to Alexander S. Häusl (alexander.haeusl@biophyll.com) and Mathias V. Schmidt (mschmidt@psych.mpg.de)

Disturbed activation or regulation of the stress response through the hypothalamic-pituitary-adrenal (HPA) axis is a fundamental component of multiple stress-related diseases, including psychiatric, metabolic and immune disorders. The FK506 binding protein 51 (FKBP5) is a negative regulator of the glucocorticoid receptor (GR), a main driver of HPA axis regulation, and FKBP5 polymorphisms have been repeatedly linked to stress-related disorders in humans. However, the specific role of Fkbp5 in the paraventricular nucleus of the hypothalamus (PVN) in shaping HPA axis (re)activity remains to be elucidated. Using deletion, overexpression, and rescue of Fkbp5 exclusively in the PVN, we establish the fundamental importance of Fkbp5 in the HPA axis stress response. Furthermore, we show that Fkbp5 manipulation alters GR activation and elucidate the cellular complexity in the PVN, in which Fkbp5 operates.

\section{Introduction}

Life is full of challenges and appropriate coping with such events implies proper activation and termination of the stress response. The hypothalamic-pituitary-adrenal (HPA) axis is the central orchestrator of the stress response and its end product glucocorticoids (cortisol in humans, corticosterone (CORT) in rodents) mediates the adaptation to acute and chronic stressors in peripheral tissues as well as in the brain ${ }^{1}$. A hallmark of HPA axis regulation is the negative feedback on the secretion of stress hormones to terminate the stress response which is controlled by glucocorticoids via the GR.

A critical regulator of $G R$ and therefore key to a successful termination of the stress response is FK506 binding protein 51 (FKBP5), which is encoded by the FKBP5 gene ${ }^{2}$. FKBP5 is a Hsp90associated co-chaperone that restricts $G R$ function by reducing ligand binding, delaying nuclear translocation, and decreasing GR-dependent transcriptional activity ${ }^{3,4}$. Hence, higher levels of FKBP5 mRNA are associated with higher levels of circulating cortisol and reduced negative feedback inhibition of the stress response ${ }^{5-9}$. Consequently, GR-induced FKBP5 levels reflect the environmental stress condition, and as such, FKBP5 expression has been used as a stress-responsive gene marker ${ }^{10}$. Importantly,
FKBP5 polymorphisms have been consistently associated with stress-related psychiatric disorders such as major depression and PTSD $^{11-13}$, where a demethylation-mediated increase in FKBP5 expression was identified as causal in risk-allele carriers ${ }^{14}$.

Despite the central importance of FKBP5 in stress system biology and stress-related disorders, detailed functional and mechanistic studies are still largely missing. Only a few human post-mortem studies focus on central tissue in order to dissect FKBP5 mechanisms, while the majority of studies use peripheral blood mononuclear cells (PBMCs) as a correlate of FKBP5 brain activity $^{15}$. Most of the animal data were obtained from wild-type (WT) or conventional Fkbp5 knockout mice, thereby lacking cell type-specific insights of Fkbp5 function ${ }^{8,16}$. To tackle this paucity of information, we here investigate the specific role of Fkbp5 in the paraventricular nucleus of the hypothalamus (PVN) the key brain region orchestrating the stress response. Using site-specific manipulations of $F k b p 5$, single-cell RNA expression profiling, and functional downstream pathway analyses, our data unravel a key role of PVN Fkbp5 in shaping the body's stress system (re)activity, with important implications for its contribution to stress-related disorders.

\section{Results}

Loss of Fkbp5 in the PVN alters HPA axis physiology.

To study the effects of Fkbp5 in the PVN, we first generated PVNspecific conditional Fkbp5 knockout mice $\left(F k b p 5^{\mathrm{PVN}-/}\right)$ by crossing $F k b p 5^{\text {lox/lox }}$ mice (generated in-house; for details see online methods) with the Sim1-Cre mouse line, which expresses Cre recombinase in $\mathrm{Sim}^{+}$neurons mostly concentrated within the PVN (Figure 1A). The successful deletion of Fkbp5 in the PVN was assessed by mRNA and protein analysis (Figure 1B, Supplementary Figure 1). Under basal conditions, adult mice lacking Fkbp5 in the PVN showed significantly lower body-, and adrenal weights, and higher thymus weights compared to their WT littermates (Figure 1C). Interestingly, $F k b p 5^{\mathrm{PVN}-/-}$ mice in young adolescence showed no significant differences in body weight, 


\section{A Breeding scheme}

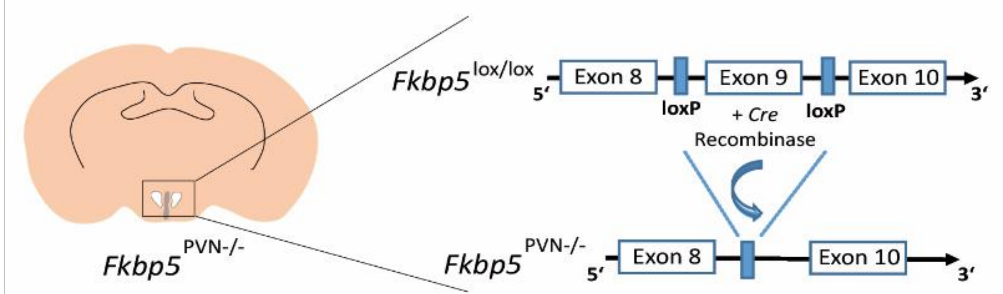

C Body physiology
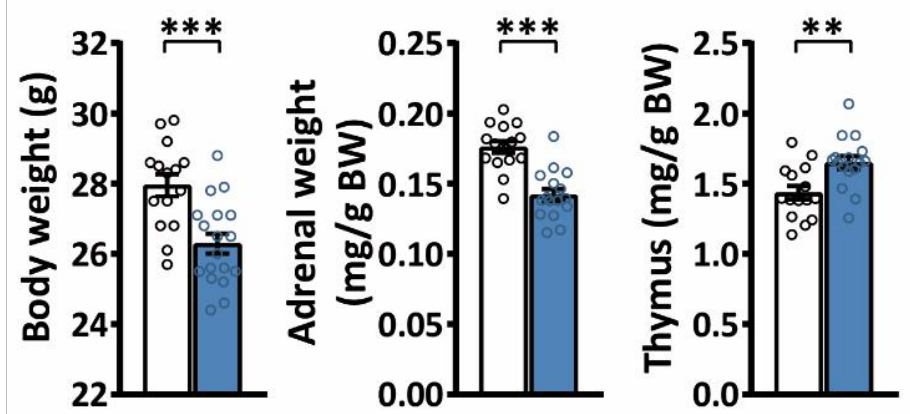

D Acute stress response
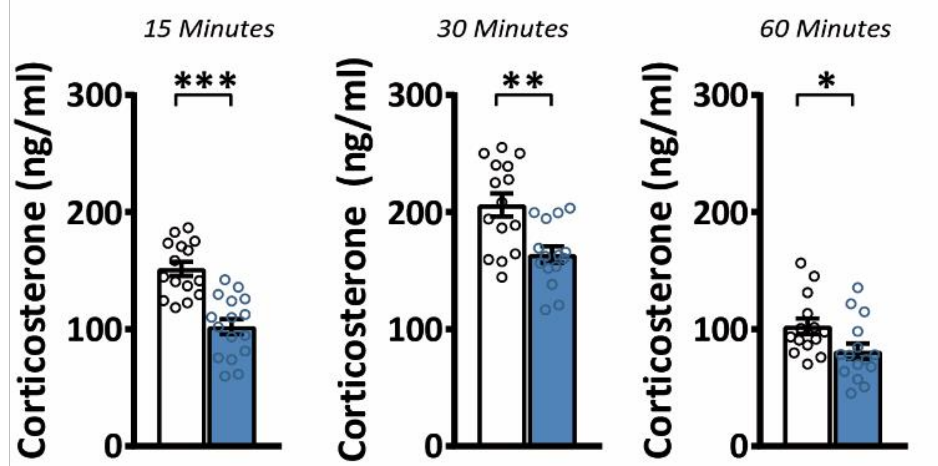

\section{B Validation of Fkbp5 deletion}

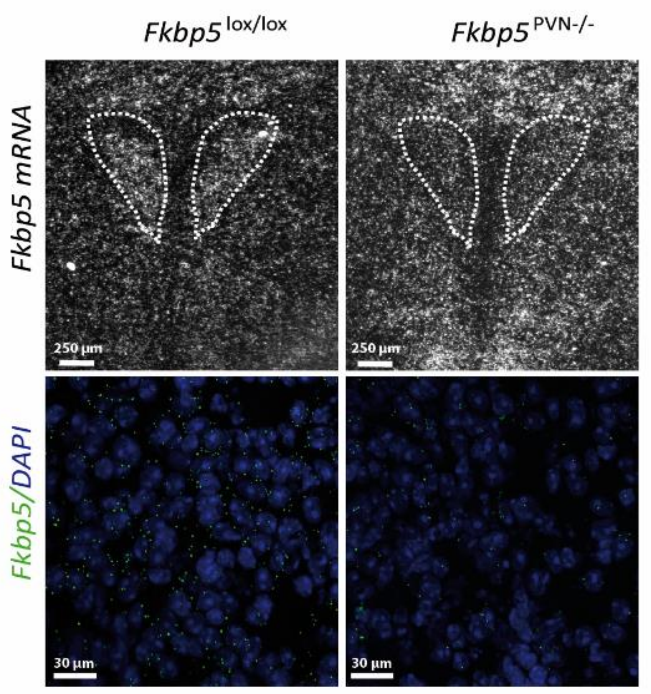

E Combined Dex/CRH Test

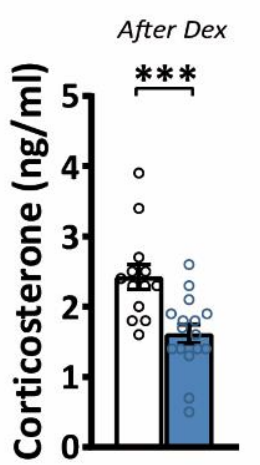

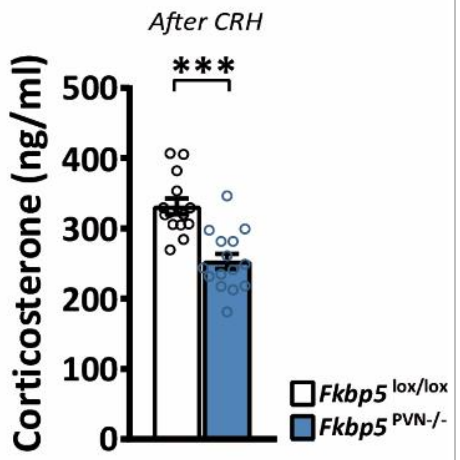

Figure 1: Loss of Fkbp5 in the PVN alters HPA axis physiology. (A) Cre-LoxP based generation of the Fkbp5 $5^{\mathrm{PVN}-/-}$ mouse line. (B) Validation of Fkbp5 mRNA expression in the PVN via In-Situ hybridization (ISH) and RNAscope. (C) $F k b p 5^{\mathrm{PVN}-/-}$ mice $(\mathrm{n}=16$ ) presented reduced body weight, lowered adrenal weights and increased thymus weights under non-stressed conditions compared to their WT littermates $(n=15)$. (D) Corticosterone levels were significantly reduced following a 15 minutes restraint stress until at least 60 minutes after stress onset. (E) A combined Dex/CRH test showed a significantly pronounced response to a low dose of dexamethasone as well as a dampened response to $\mathrm{CRH}$ injection. Data are presented as mean $\pm \mathrm{SEM}$. All data were analyzed with a student's t-test. ${ }^{*}=p<0.05, * *=p<0.01$ and ${ }^{* * *}=p<0.001$.

adrenal or thymus weights (Supplementary Figure 2), indicating an age-dependent phenotype of Fkbp5 in the HPA-axis' response.

As PVN Fkbp5 mRNA levels are highly responsive to an acute stressor $^{10}$, we hypothesized that $F k b p 5^{\mathrm{PVN}-/}$ mice have an altered stress response following an acute challenge. Under basal conditions during the circadian trough, no differences in corticosterone secretion were detected in young and adult mice (Supplementary Figure 1 and 2). However, already after 15 minutes of restraint stress $F k b p 5^{\mathrm{PVN}-/}$ displayed significantly reduced plasma corticosterone levels compared to the control group (Figure 1D). The dampened stress response was persistent for 60 minutes after stress onset, while levels of the adrenocorticotropic hormone (ACTH) were not altered under basal or acute stressed conditions (Supplementary Figure 1).

To further investigate the effect of Fkbp5 on GR sensitivity, we performed a combined dexamethasone (Dex, a synthetic GC) corticotropin-releasing hormone (CRH) test. The combined Dex/CRH test is a method to analyze HPA axis (dys)function in depressed individuals or animals, measuring the responsiveness of the body's stress response system through suppression (by Dex injection) and stimulation (by CRH injection) of the HPA axis ${ }^{17}$. The injection of a low dose of Dex $(0.05 \mathrm{mg} / \mathrm{kg})$ resulted in a reduction in blood corticosterone levels compared to the evening corticosterone levels in both groups. Interestingly, mice lacking Fkbp5 in the PVN showed 1.5-fold lower levels of corticosterone compared to their WT littermates. Following CRH stimulation (0.15 mg/kg) Fkbp5 $5^{\mathrm{PVN}-/ \text { - }}$ mice showed a significantly lower reaction to $\mathrm{CRH}$ than control mice (Figure $1 \mathrm{E}$ ). These data indicate that specific deletion of $F k b p 5$ in the PVN dampens HPA axis response and enhances GR sensitivity.

Overexpression of Fkbp5 in the PVN induces a stress-like phenotype in C57BI/6 mice under basal conditions.

Chronic or acute stress upregulates Fkbp5 in distinct brain regions, such as the $\mathrm{PVN}^{10}$. Therefore, we were interested to explore whether selective overexpression of Fkbp5 in the PVN would be sufficient to affect body physiology and stress system regulation. To do so, we bilaterally injected $200 \mathrm{nl}$ of an adenoassociated virus (AAV) containing a Fkbp5 overexpression vector 


\section{A Experimental procedure}

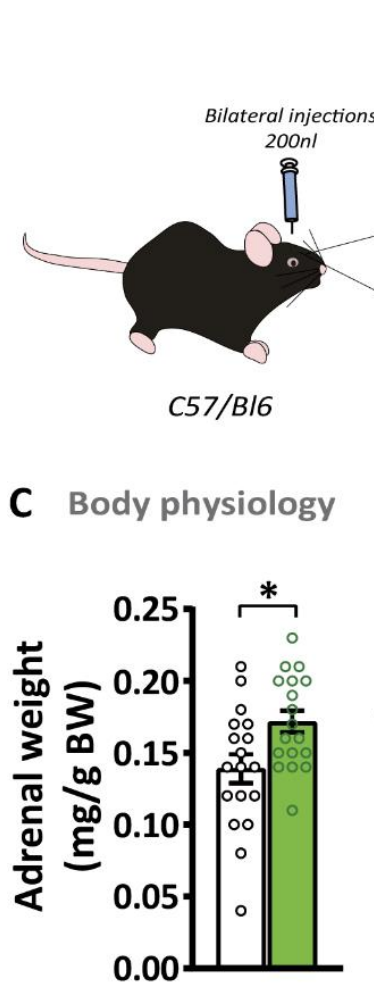

Fkbp5 OE virus - CAG - HA - human Fkbp5 - WPRE - BGH - polyA Control virus - CAG - Null - Empty - WPRE - BGH - polyA
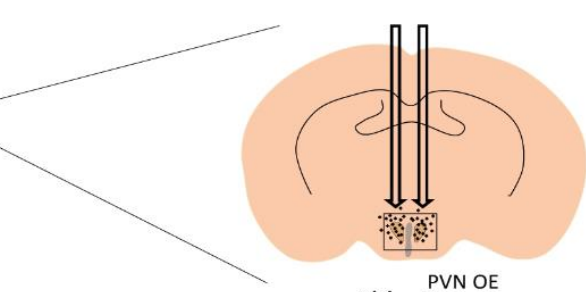

Fkbp5 $5^{\text {PVN OE }}$

D Basal corticosterone level
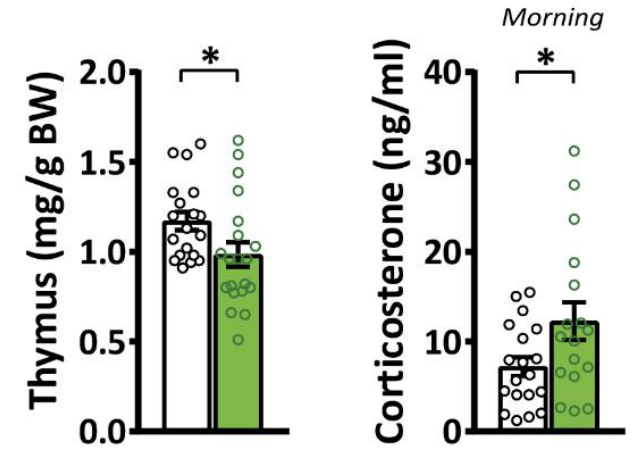

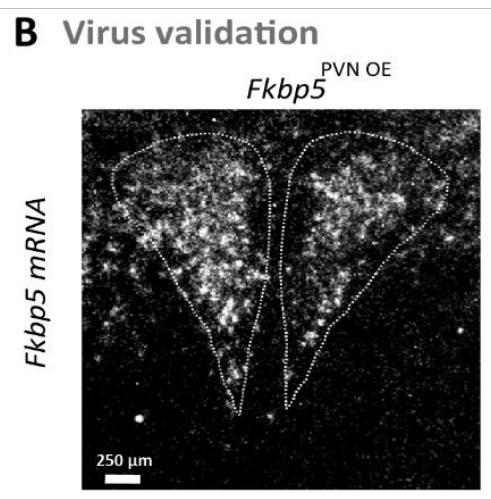

E Acute stress response

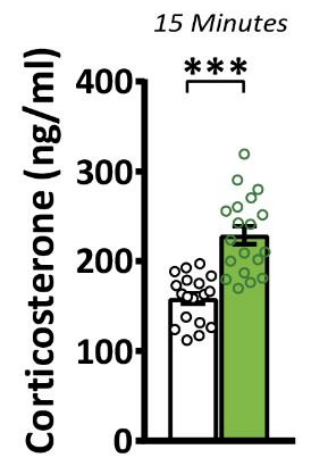

Evening

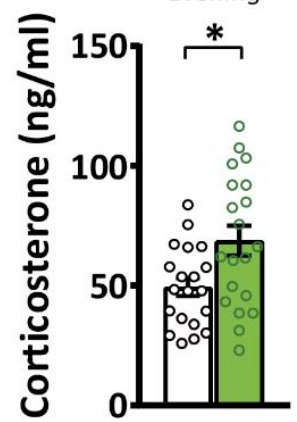

F Combined Dex/CRH Test
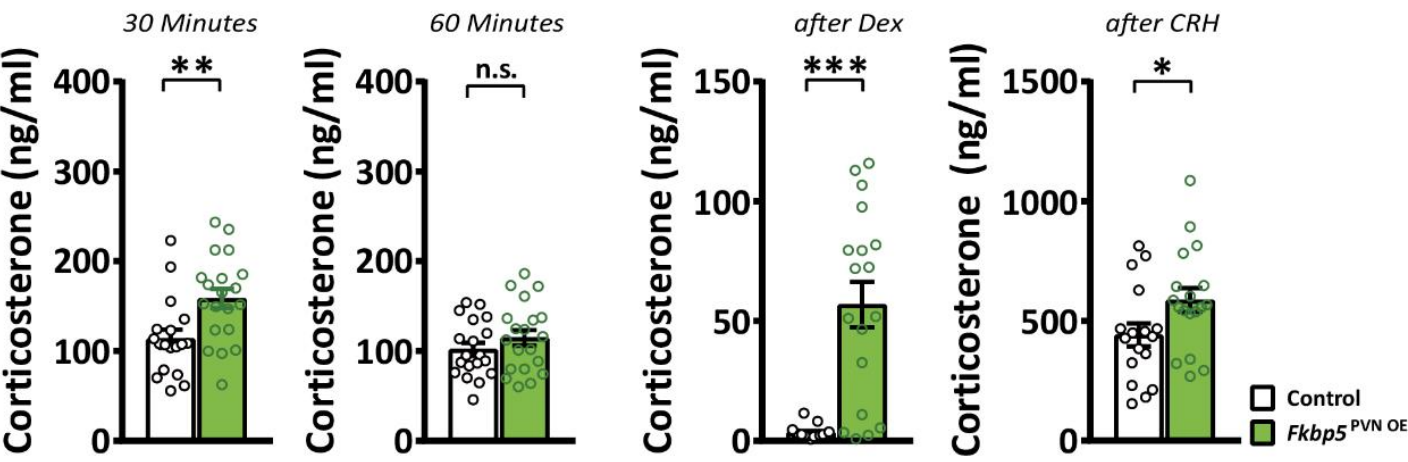

Figure 2: The overexpression of $F k b p 5$ in $\mathrm{C} 57 \mathrm{Bl} / 6$ mice induces stress-like phenotype under basal conditions. (A) Overexpression of Fkbp5 in the PVN was achieved by bilateral viral injections. (B) Validation of $F k b p 5$ mRNA overexpression in the PVN by ISH. (C) $F k b p 5^{\mathrm{PVN}}$ ${ }^{O E}$ mice $(n=20)$ showed significantly increased adrenal weights and a reduced thymus weight under non-stressed conditions compared to the controls $(n=20)$. (D) Fkbp5 overexpression resulted in heightened corticosterone levels during the day. (E) 15 and 30 minutes after stress onset, $F k b p 5^{\mathrm{PVN} O E}$ mice displayed significantly higher corticosterone levels. (F) Fkbp5 ${ }^{\mathrm{PVN} O \mathrm{OE}}$ mice showed significantly elevated corticosterone $6 \mathrm{~h}$ after dexamethasone treatment. The following $\mathrm{CRH}$ injection further significantly increased the corticosterone release compared to controls. Data are presented as mean \pm SEM. All data were analyzed with student's t-test. ${ }^{*}=p<0.05, * *=p<0.01, * * *=p$ $<0.001$, n.s. $=$ not significant.

into the PVN of young adult (10 weeks) C57BI/6 mice ( $F k b p 5^{\mathrm{PVN}}$ $\mathrm{OE}$, Figure $2 \mathrm{~A}-\mathrm{B})$. The AAV-mediated overexpression resulted in a (4-fold) increase in Fkbp5 mRNA and protein levels (Fkbp5) in the PVN (Supplementary Figure 3).

Intriguingly, Fkbp5 overexpression altered the physiology of stress responsive organs. $F k b p 5^{\mathrm{PVN}}$ OE animals showed a significantly reduced thymus weight and increased adrenal weights compared to their littermates (Figure 2C), the hallmark of chronically stressed animals ${ }^{18,19}$. Furthermore, overexpression of Fkbp5 affected the circadian rhythm of corticosterone secretion, indicated by increased blood corticosterone levels in the morning as well as the evening (Figure 2D). Consequently, ACTH levels of $F k b p 5^{\mathrm{PVN} O E}$ animals were also

increased under non-stressed conditions (Supplementary Figure 3). Next, we analyzed distinguished stress markers under basal conditions in order to determine whether consequences of PVNspecific Fkbp5 overexpression are also detectable at the molecular level. Interestingly, $\mathrm{Nr} 1 \mathrm{c3}$ and $\mathrm{Crh}$ mRNA expression in the PVN were increased in $F k b p 5^{\mathrm{PVN} O E}$ animals compared to controls, whereas Avp mRNA levels were not altered (Supplementary Figure 3). Together, these results are comparable to chronically stressed animals and demonstrate that local overexpression of Fkbp5 in the PVN is sufficient to 


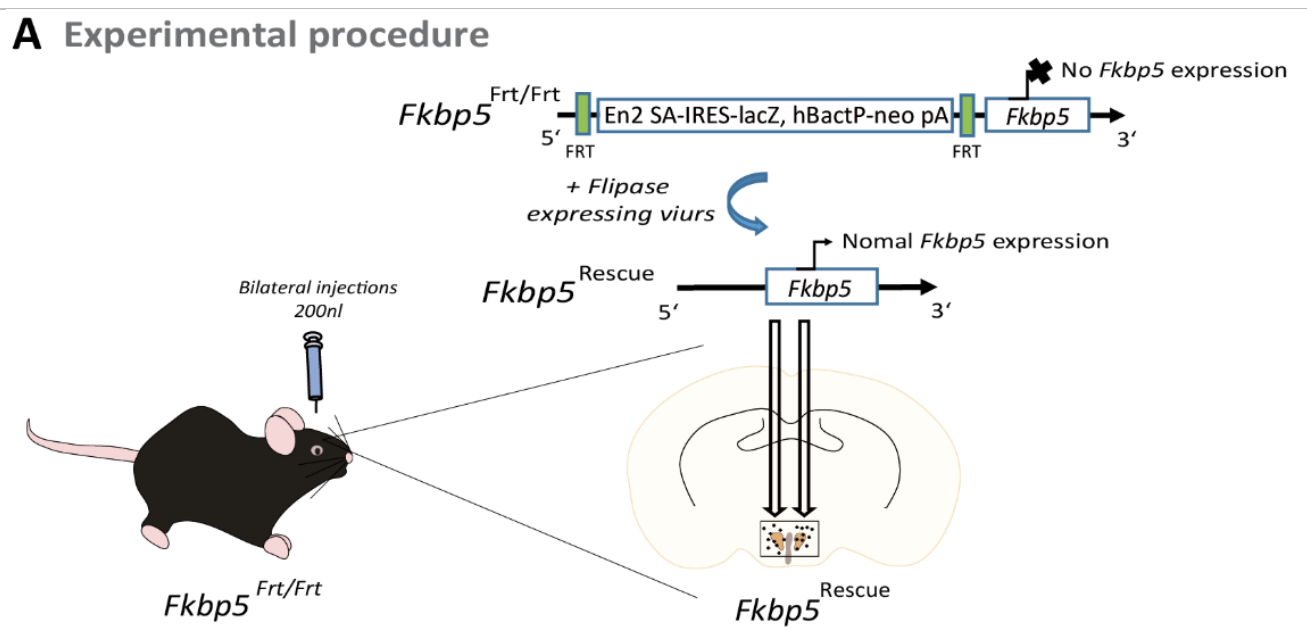

\section{B Virus validation}

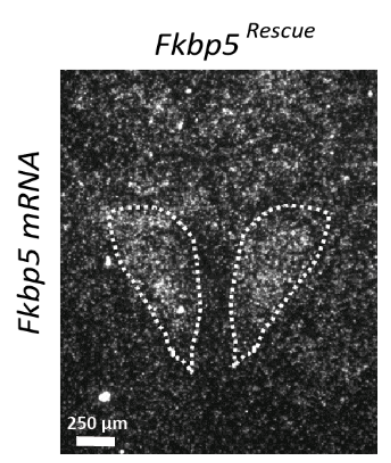

\section{Body physiology}

D Basal corticosterone level

E Acute stress response
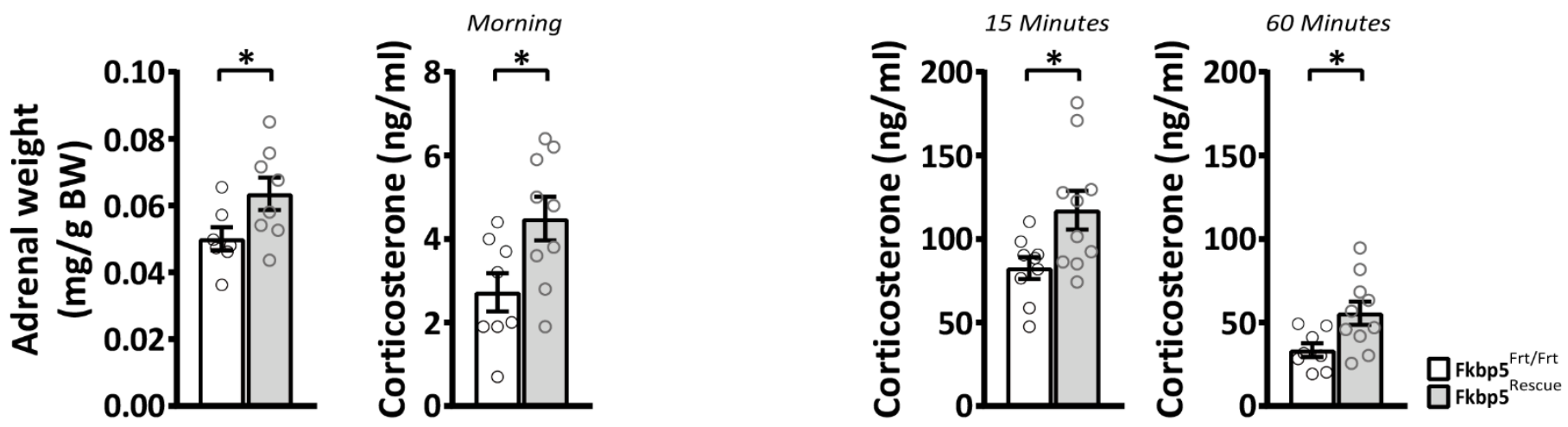

Figure 3: The reinstatement of endogenous Fkbp5 in the PVN of global Fkbp5 knock-out animals. (A) Experimental procedure. (B) Validation of successful Fkbp5 rescue by ISH. (C) The reinstatement of Fkbp5 in the PVN resulted in increased adrenal weights and elevated morning corticosterone levels under basal conditions (D). Furthermore, Fkbp5 re-instated animals displayed a significantly higher corticosterone response after restraint stress $(E)$. Data are presented as mean \pm SEM. All data were analyzed with student's t-test. ${ }^{*}=p<0.05$.

mimic a stress-like phenotype without physically challenging the animals.

In accordance to the knock-out studies with the $F k b p 5^{\mathrm{PVN}-\text { - }}$ animals, we investigated the endocrinology of $F k b p 5^{\mathrm{PVN}}$ OE animals after an acute challenge. As expected, we detected higher blood corticosterone levels in Fkbp5 $5^{\mathrm{PVNOE}}$ mice 15 and 30 minutes after stress onset compared to the stressed controls (Figure 2E). However, we could not detect any difference in ACTH release (Supplementary Figure 3). No differences between both groups were observed at 60 and 90 minutes after restraint stress (Figure 2E, Supplementary Figure 3). These data show that $F k b p 5^{\mathrm{PVN} O E}$ mice have a hyperactive HPA axis response and are more vulnerable to acute stress exposure.

To further assess GR sensitivity in Fkbp5 overexpressing animals, we again tested the response to a combined Dex/CRH test. While control animals showed a decline $(<5 \mathrm{ng} / \mathrm{ml})$ in blood corticosterone levels $6 \mathrm{~h}$ after Dex injection, $\mathrm{Fkbp5} 5^{\mathrm{PVN} O E}$ mice showed almost no response to Dex treatment (Figure 2F). Interestingly, the subsequent $\mathrm{CRH}$ injection resulted in a higher corticosterone release in $\mathrm{Fkbp5} 5^{\mathrm{PVN} O \mathrm{E}}$ mice compared to controls (Figure 2F). These results suggest that excess levels of Fkbp5 in the PVN lead to a decreased GR sensitivity and thereby to an altered HPA axis response. Taken together, animals overexpressing Fkbp5 in the PVN show a hyperactive function of the HPA axis under basal and acute stress conditions, thereby mimicking the physiological hallmarks of chronic stress exposure and HPA axis hyperactivity, as observed in multiple stress-related diseases ${ }^{20}$.

Reinstatement of endogenous Fkbp5 in the PVN of global Fkbp5 knock-out animals normalizes the body's stress response.

Global loss of Fkbp5 results in a more sensitive GR and better coping behavior of mice after stress ${ }^{8,15,18,21}$. Our results showed that Fkbp5 in the PVN is necessary for an undisturbed stress system function. To investigate whether $F k b p 5$ function in the PVN is sufficient to restore a "normal" HPA axis (re)activity, we aimed to re-instate native Fkbp5 expression in global Fkbp5 knock-out animals selectively in the PVN. Therefore, we injected a Flp recombinase expressing virus into $\mathrm{Fkbp} 5^{\mathrm{Frt} / \mathrm{Frt}}$ mice. These mice carry a FRT flanked reporter selection (stop) cassette within the Fkbp5 locus, leading to a disruption of Fkbp5. Flp removes the stop cassette from the $F k b p 5$ locus, resulting in endogenous Fkbp5 re-expression (Figure 3A-B, Supplementary Figure 4). In parallel to the two previous mouse models, we assessed body physiology, basal corticosterone levels, and the acute stress response. Interestingly, mice with re-instated Fkbp5 expression $\left(F k b p 5^{\text {PVN Rescue }}\right)$ showed significantly higher adrenal weights as compared to their control littermates (Figure $3 \mathrm{C}$ ). Furthermore, we observed that the reinstatement of Fkbp5 in the PVN resulted in significantly increased blood CORT levels in the morning under basal conditions (Figure 3D), with no effect on 

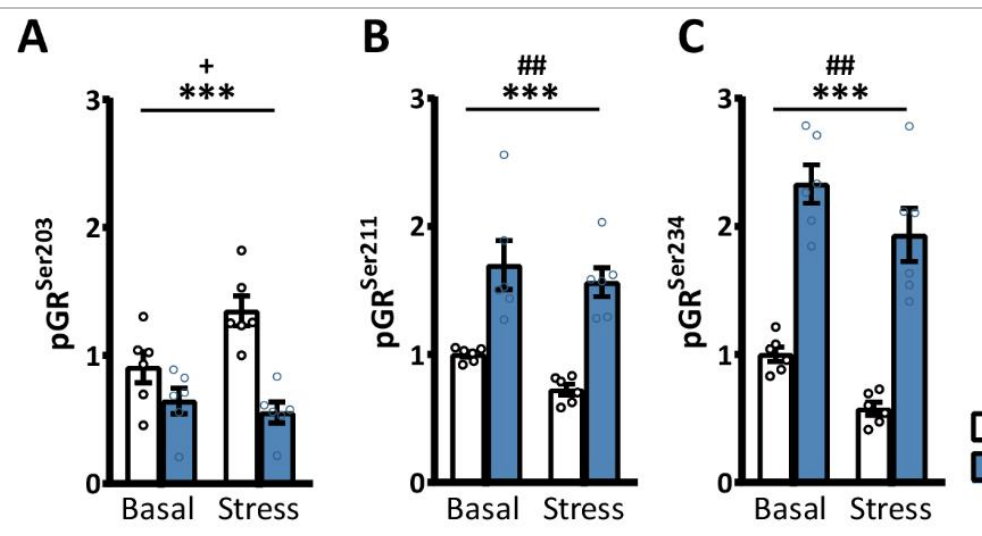

D

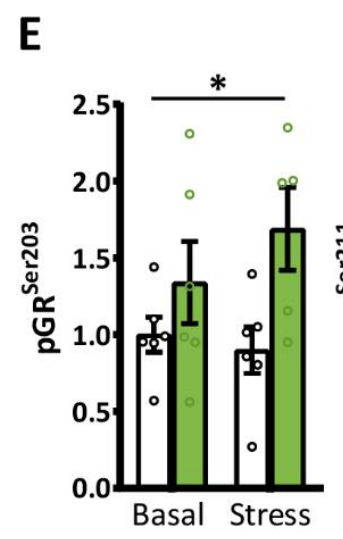

$\mathbf{F}$
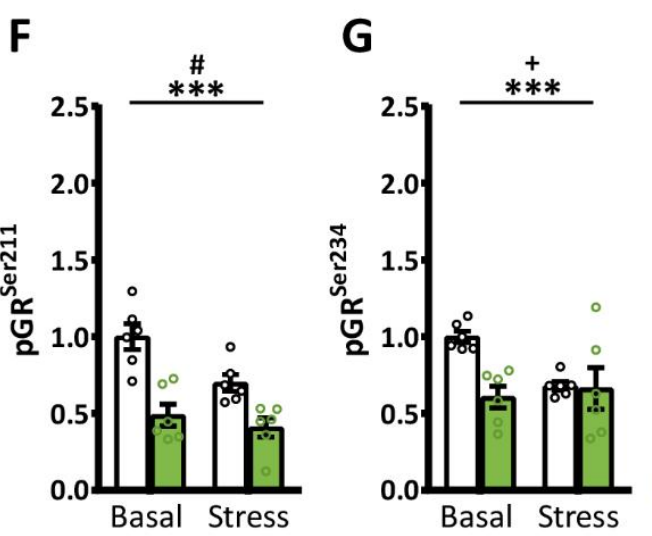

H
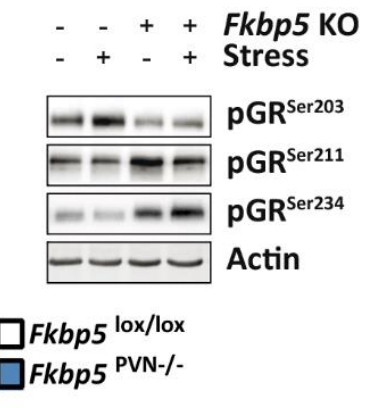

-++ Fkbp5 OE

-+-+ Stress

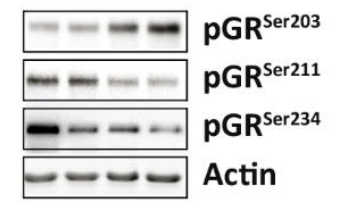

Figure 4: Fkbp5 manipulation affects phosphorylation of the glucocorticoid receptor (GR). (A) Animals lacking Fkbp5 in the PVN showed significantly lower phosphorylation at $\mathrm{pGR}^{\mathrm{Ser} 203}$ and higher levels of $\mathrm{pGR}^{\mathrm{Ser} 211}$ (B) and $\mathrm{pGR}^{\mathrm{Ser234}}$ (C) compared to the control animals. Fkbp5 ${ }^{\mathrm{PVN}}$ ${ }_{\mathrm{OE}}$ animals showed the opposite effect on GR phosphorylation with higher phosphorylation on $\mathrm{pGr}^{\text {Ser203 }}$ (E). Additionally, we observed a significantly lower phosphorylation at the GR sites $\operatorname{Ser}^{211}$ (F) and $\operatorname{Ser}^{234}$ (G). Representative blots are shown in (D) and (H). Group size for A-H: 6 vs. 6. Data are presented as mean \pm SEM and were analyzed with a two-way ANOVA. ${ }^{*}=$ significant genotype effect, $\left({ }^{*}=p<0.05, * *=p<\right.$ $0.01, * * *=p<0.001) .+=$ significant genotype $x$ stress interaction $(+=p<0.05)$, $\#=$ significant stress effect $(\#=p<0.05, \# \#=p<0.01)$.

thymus weights, evening CORT, and basal ACTH levels (Supplementary Figure 4). ISH analysis revealed significant higher levels of $\mathrm{Crh}$ mRNA, but no changes in Nr1c3 and Avp mRNA expression in the PVN (Supplementary Figure 4). Next, we monitored blood corticosterone levels after 15 minutes of restraint stress. Here, we observed significantly higher CORT levels 15 and 60 minutes after stress onset (Figure 3E). Intriguingly, no differences were detected in the combined Dex/CRH test (Supplementary Figure 4), indicating that a PVNdriven over-activation of the HPA axis is necessary for a desensitization of GRs in the PVN and the pituitary. These rescue experiments underline the importance of Fkbp5 in the acute stress response and demonstrate that Fkbp5 in the PVN is necessary and sufficient to regulate HPA axis (re)activity.

\section{Fkbp5 manipulation directly affects GR phosphorylation.}

It is well known that ligand-binding induced phosphorylation of GR plays an important role in response to hormone signaling ${ }^{22}$. The main phosphorylation sites involved in hormone signaling of GR are at Serine(Ser) ${ }^{203}$ (mouse $S^{212}$ ), $\operatorname{Ser}^{211}$ (mouse Ser ${ }^{220}$ ) and $\operatorname{Ser}^{226}$ (mouse $\mathrm{Ser}^{234}$ ) and are associated with GR activity ${ }^{22,23}$. Here, we tested the hypothesis that the co-chaperone Fkbp5 regulates phosphorylation of $\mathrm{GR}$ in $\mathrm{Fkbp5} 5^{\mathrm{PVN}-/}$ and $\mathrm{Fkbp5} 5^{\mathrm{PVN} \text { OE }}$ mouse lines. To do so, we dissected the PVN of $F k b p 5^{\mathrm{PVN}-/}$ and $F k b p 5^{\mathrm{PVN} O E}$ mice and measured the phosphorylation levels of $\mathrm{Ser}^{203}, \mathrm{Ser}^{211}$, and $\mathrm{Ser}^{234}$ under basal and stress conditions.
Under basal conditions, animals lacking Fkbp5 in the PVN showed significantly less GR phosphorylation at $\operatorname{Ser}^{203}$ (Figure

4A). Furthermore, $F k b p 5^{\mathrm{PVN}-/-}$ animals displayed higher phosphorylation of GR at $\operatorname{Ser}^{234}$ and $\operatorname{Ser}^{211}$ in comparison to their WT littermates (Figure 4B-C). Under stressed conditions, deletion of Fkbp5 had the same effects on $p G R^{\mathrm{Ser} 211}$ and $p G R^{\mathrm{Ser} 234}$ as we observed under basal conditions (Figure 4B-C). Levels of $p G R^{\text {Ser203 }}$ were found to be unchanged in the $F k b p 5^{\mathrm{PVN}-\gamma_{-}}$after an acute stress compared to the basal levels. However, $\mathrm{pGR}^{\mathrm{Ser} 203}$ levels of the control group increased after stress (Figure 4A).

Intriguingly, $F k b p 5^{\mathrm{PVN} O E}$ animals showed exactly the opposing phenotype at all three phosphorylation sites with less $\mathrm{pGr}^{\text {Ser234 }}$ and $\mathrm{pGr}^{\mathrm{Ser211}}$ and higher phosphorylation at $\mathrm{Ser}^{203}$ under basal conditions (Figure $4 \mathrm{E}-\mathrm{G}$ ). In parallel to the unstressed condition, the overexpression of $F k b p 5$ resulted in less GR phosphorylation at $\operatorname{Ser}^{211}$ and higher levels of $p G R^{\mathrm{Ser} 203}$ compared to their control group after stress (Figure $4 \mathrm{E}-\mathrm{F}$ ). Interestingly, levels of $\mathrm{pGR}^{\mathrm{Ser} 234}$ were unchanged after stress (Figure 4G). Notably, total GR levels were not significantly altered in both experimental groups and conditions (Supplementary Figure 5). Despite the altered GR phosphorylation, we could not detect any significant changes in GR enrichment at the glucocorticoid response element (GRE) in the Crh gene after acute stress (Supplementary Figure 6), which may be due to the use of an antibody that recognizes all GR molecules irrespective of its phosphorylation state. 


\section{A Overview single cell sequencing}

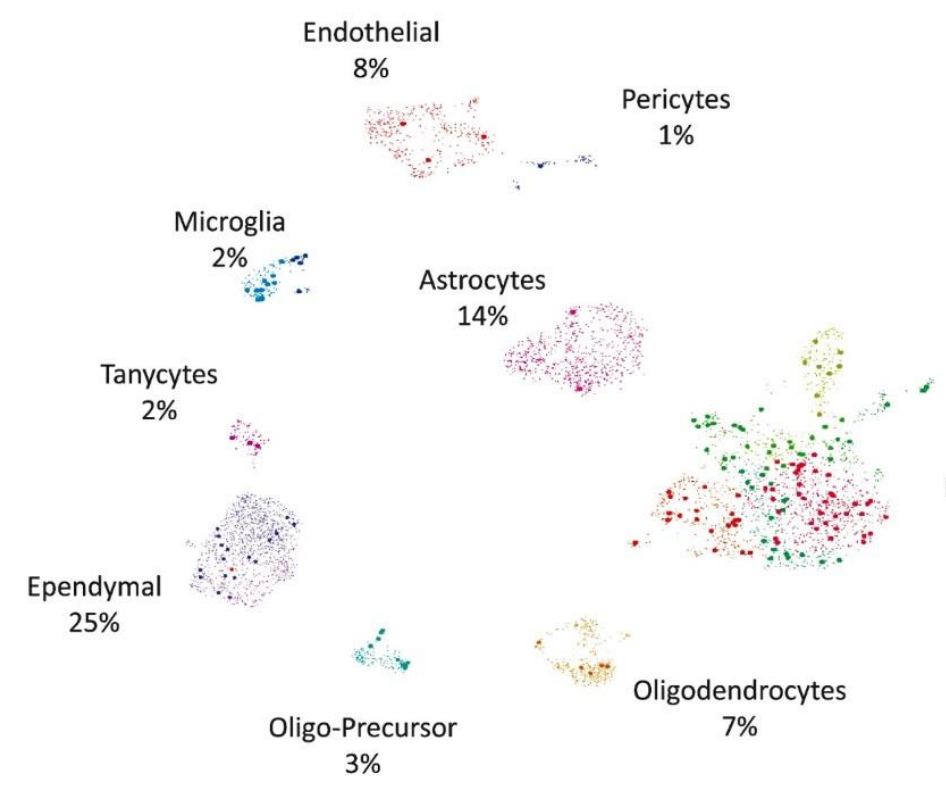

\section{B Main neuronal markers}

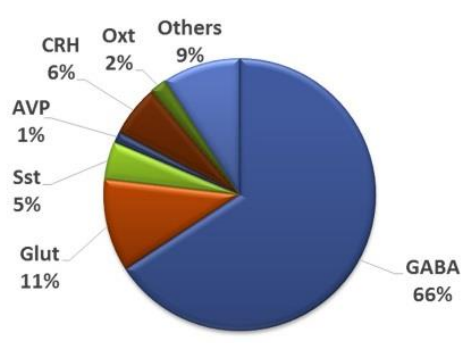

\section{Fkbp5+cell population}

Neurons $38 \%$

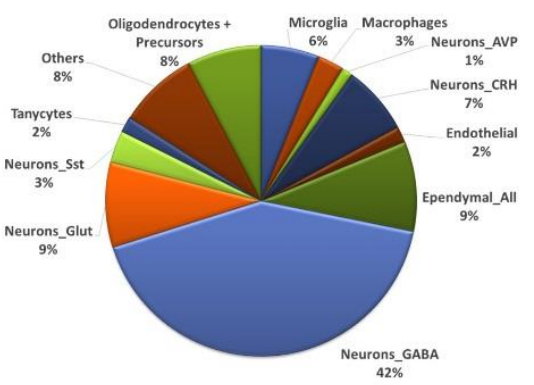

Figure 5: Single-cell RNA sequencing of cells in the PVN under non-stressed conditions. (A) Single-cell sequencing depicted several different cell types. With the majority being neurons (38\%), ependymal cells (25\%) and astrocytes (14\%). Fkbp $5^{+}$cells are highlighted. (B) Neurons could be divided mostly into GABAergic (66\%) and glutamatergic (Glut, $11 \%$ ) cells. Furthermore, the well-known stress markers corticotropin-releasing hormone (Crh, 6\%), somatostatin (Sst, 5\%), oxytocin (Oxt, 2\%) and vasopressin (Avp, 1\%) could be detected under basal conditions. (C) Diversity of $F k b p 5^{+}$cell population.

Overall our data demonstrate that Fkbp5 manipulation in the PVN affects GR phosphorylation at all three major phosphorylation sites. Furthermore, it suggests that Fkbp5 affects GR phosphorylation and that the changed phosphorylation, at least partly, leads to the corticosterone phenotype in $F k b p 5^{\mathrm{PVN}-/}$ and $F k b p 5^{\mathrm{PVN} O \mathrm{E}}$ animals by altering GR activity.

\section{Fkbp5 in the PVN acts in a complex cellular context.}

To further unravel the expression profile of Fkbp5 in the PVN and to detect cellular populations that might be mediating the effects of Fkbp5 on HPA axis control, we used a single-cell RNA sequencing dataset consisting of 5,113 single cells isolated from the PVN. The single-cell expression data reveal a complex cellular composition, with the majority of cells identified as neurons (38\%), ependymal cells (25\%) and astrocytes (14\%) (Figure 5A-B). Fkbp5 was found to be differentially and cell-type specifically expressed, with the biggest Fkbp5+ cell population found in GABAergic neurons (42\%). A significant expression of Fkbp5 was also detected in neuronal populations known to be directly involved in HPA axis regulation, most prominently in $\mathrm{Crh}$ positive neurons (Figure $5 \mathrm{C}$ ). However, it is important to point out that the expression levels of $F k b p 5$ are relatively low. Unfortunately, lowly expressed genes may not be detected using this technique ${ }^{24}$ and therefore many Fkbp5 positive cells may have remained undetected in this dataset. To circumvent this

problem, we next performed a targeted co-expression study of Fkbp5 with five major markers that are characteristic of the stress response oxytocin (Oxt), somatostatin (Sst), vasopressin
(Avp), thyrotropin releasing hormone (Trh), and Crh under basal and stress conditions (Figure 6). We observed a strong but not complete co-localization of Fkbp5 expression with these neuropeptide-expressing cellular populations in the PVN under basal conditions. Interestingly, a detailed quantification of the change in co-expression following stress revealed that there was a significant increase in Crh-Fkbp5 co-localization only in the Crh-expressing neurons (Figure 6, Suppl. Fig 7).

These data reveal the complex cell type specific expression pattern of Fkbp5 under stress and basal conditions in the PVN. Furthermore, they indicate a crucial role of Fkbp5 in Crh positive neurons after an acute stress challenge.

\section{Discussion}

FKBP5 was first associated with stress-related disorders in $2004^{13}$ and has been studied extensively over the past 15 years with regard to stress regulation and sensitivity. However, detailed cell-type and region-specific manipulations of Fkbp5 in the brain are still lacking. In this study, we highlight the importance of this co-chaperone in the regulation of the acute stress response through the combined analysis of deletion, overexpression, and rescue of Fkbp5 exclusively in the PVN.

Fkbp5 is a stress responsive gene and past research has shown that its main effects occur after chronic or acute stress ${ }^{8,16,21,25,26}$. Given that deletion of $F k b p 5$ in the PVN mimics the previously described phenotype of $F k b p 5 \mathrm{KO}$ mice ${ }^{21}$, with regard to their basal neuroendocrine profile and HPA axis function, our data illustrate that the functional contribution of Fkbp5 to HPA axis 


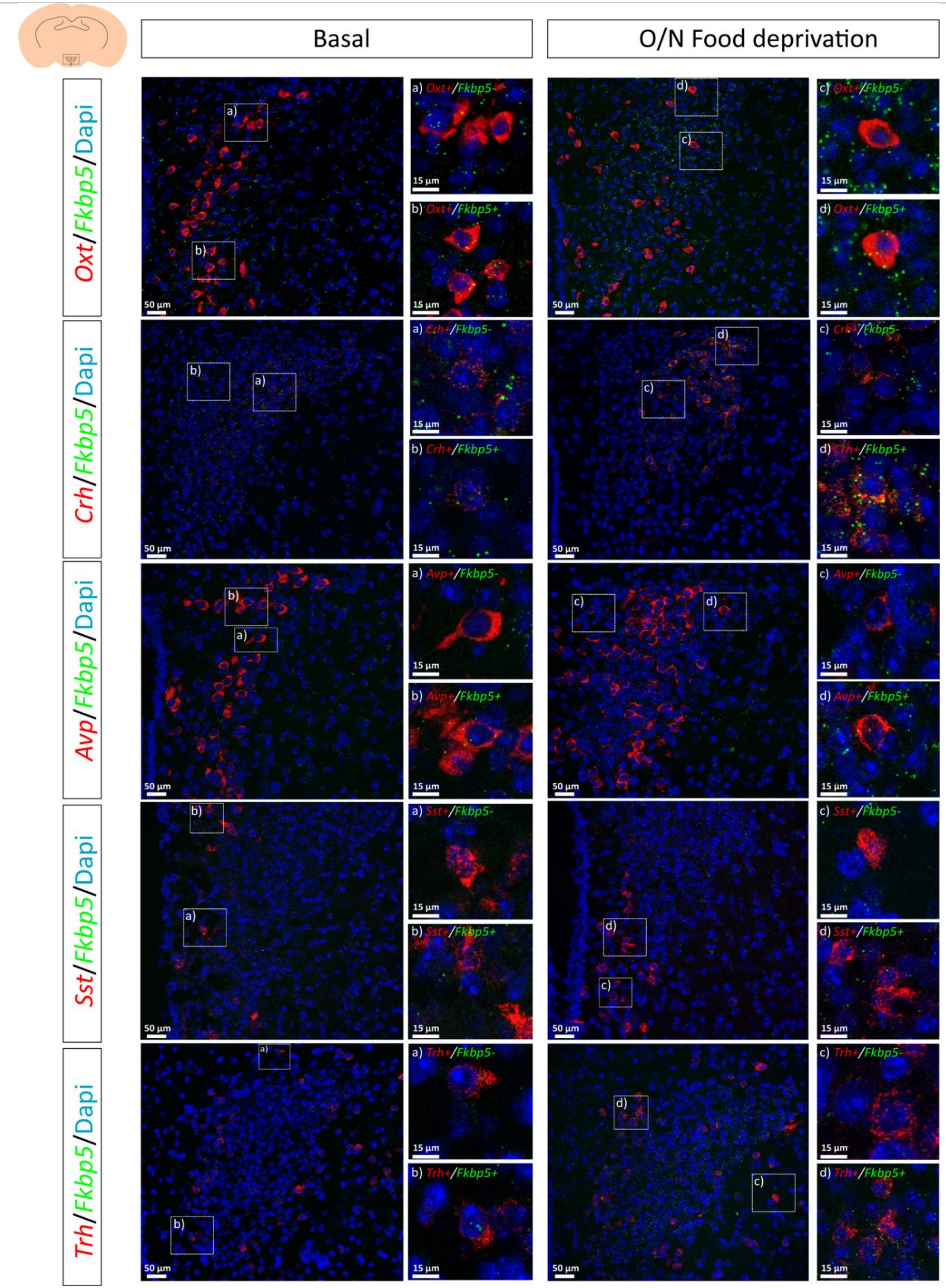

Figure 6: RNAscope analysis of Fkbp5 expression in stress response neuronal cell populations under basal and stressed conditions. In comparison to single-cell sequencing, RNAscope revealed a significant higher co-localization ratio of Fkbp5 in oxytocin (Oxt), corticotropin-releasing hormone (Crh), vasopressin (Avp), somatostatin (Sst) and thyronine releasing hormone (Trh) neurons. Overnight food deprivation increased $F k b p 5$ mRNA in all cell populations.

activity is centered in the PVN. In addition, reinstatement of native basal Fkbp5 expression in the PVN of Fkbp5 KO mice was sufficient to normalize HPA axis function. Interestingly, the phenotype of intensified HPA axis suppression due to the loss of Fkbp5 in the PVN emerges only in adult animals, excluding developmental effects and underlining the previously reported importance of Fkbp5 in ageing ${ }^{27,28}$.

Further, our results highlight the essential role of $\mathrm{Fkbp} 5$ in stress adaptation, as PVN-specific Fkbp5 excess is sufficient to reproduce all physiological and endocrinological hallmarks of a 
chronic stress situation ${ }^{29,30}$. Interestingly, the results of our $F k b p 5^{\mathrm{PVN} O E}$ cohort are comparable to the neuroendocrine effect of GR deletion in the PVN ${ }^{31}$. The consequence of a heightened Fkbp5 expression in the PVN is two-fold. Firstly, it leads to direct

changes in GR sensitivity and downstream GR signaling directly in the PVN. Secondly, PVN Fkbp5 overexpression dramatically affects GR sensitivity and feedback at the level of the pituitary, as demonstrated by the inability of a low Dex dose (that does not cross the blood-brain barrier) to suppress corticosterone secretion. This secondary effect is likely due to the constant overproduction of $\mathrm{CRH}$ in the PVN and very similar to the effects of HPA hyperactivity observed in many depressed patients ${ }^{17,32}$.

Mechanistically, we explored the role of Fkbp5 in modulating GR phosphorylation. The status of GR phosphorylation at $\mathrm{Ser}^{211}$, $\mathrm{Ser}^{203}$, and $\operatorname{Ser}^{234}$ is associated with transcriptional activity, nuclear localization, and ability to associate with GRE containing promoters $^{22}$. Whereas higher levels of phosphorylation at $\operatorname{Ser}^{211}$

are associated with full transcriptional activity and localization in the nucleus, increased phosphorylation of $\operatorname{Ser}^{203}$ is linked to a transcriptional inactive form of GR within the cytoplasm and thereby less active $\mathrm{GR}^{33-35}$. In our experiments, overexpression of Fkbp5 resulted in dephosphorylation at $\operatorname{Ser}^{211}$ and higher phosphorylation at $\mathrm{Ser}^{203}$, suggesting that the GR is mostly located in the cytoplasm and less active. Deletion of Fkbp5 showed the opposing effect, indicating a more active $G R$ in Fkbp5 $5^{\mathrm{PVN}-/-}$ animals. It has previously been reported that GR phosphorylation is regulated by several kinases, including CDK5 and $\mathrm{ERK}^{22,36}$, and Fkbp5 has also been shown to be associated with CDK5 in the brain ${ }^{37}$. Therefore, we hypothesize that Fkbp5 also interacts with CDK5 to phosphorylate GR at multiple phosphorylation sites, thereby directly affecting liganddependent GR activity.

Given the complexity of the different cell types with highly specialized functions in the brain, it is essential to gain a deeper understanding of the cellular architecture of the PVN and the specific function of Fkbp5 in this context. Previously, it was assumed that Fkbp5 is quite widely expressed in most cell types of the nervous system ${ }^{38}$. However, our current data suggest that while Fkbp5 is indeed expressed in the PVN, it is enriched in specific sub-populations, including for example GABAergic neurons, $\mathrm{Crh}^{+}$neurons and microglia, but largely absent in others, such as astrocytes and endothelial cells. Interestingly, when quantifying Fkbp5 regulation, we identified a highly selective regulation of $\mathrm{Fkbp5}$ in $\mathrm{Crh}^{+}$neurons, further supporting the central role of Fkbp5-controlled GR feedback in this neuronal subpopulation.

In summary, this study is the first to specifically manipulate Fkbp5 in the PVN and underlines its central importance in shaping HPA axis regulation and the acute stress response. The results have far-reaching implications for our understanding of stress physiology and stress-related disorders.

\section{Methods}

Animals \& animal housing. All experiments were performed in accordance with the European Communities' Council Directive 2010/63/EU. The protocols were approved by the committee for the Care and Use of Laboratory animals of the Government of Upper Bavaria, Germany. The mouse lines $F k b p 5^{\text {lox/lox }}$ and $F k b p 5^{\mathrm{PVN}-/}$ and $F k b p 5^{\mathrm{Frt} / \mathrm{Frt}}$ were generated in house. Male mice aged between 3-5 months were used for all experiments. During the experimental time, animals were kept singly housed in individually ventilated cages (IVC; $30 \mathrm{~cm} \times 16 \mathrm{~cm} \times 16 \mathrm{~cm} ; 501 \mathrm{~cm}^{2}$ ), serviced by a central airflow system (Tecniplast, IVC Green Line GM500). Animals were maintained on a $12: 12 \mathrm{hr}$ light/dark cycle, with constant temperature $\left(23 \pm 2^{\circ} \mathrm{C}\right)$ and humidity of $55 \%$ during all times. Experimental animals received ad libitum access to water and standard research diet (Altromin 1318, Altromin $\mathrm{GmbH}$, Germany) and IVCs had sufficient bedding and nesting material as well as a wooden tunnel for environmental enrichment.

Generation of Fkbp5 mice. Conditional Fkbp5 knockout mice are derived from embryonic stem cell clone EPD0741_3_H03 which was targeted by the knockout mouse project (KOMP). Frozen sperm obtained from the KOMP repository at UC Davis was used to generate knockout mice $\left(F k b p 5^{\text {tm1a(KOMP)Wtsi })}\right.$ by in vitro fertilization. These mice designated as $F k b p 5^{\mathrm{Frt} / \mathrm{Frt}}$ are capable to re-express functional Fkbp5 upon Flp recombinase-mediated excision of a frt-flanked reporter-selection cassette integrated in the Fkbp5 gene. Mice with a floxed Fkbp5 gene designated as $F k b p 5^{\text {lox/lox }}\left(F k b p 5^{\text {tm1c(KOMP)Wtsi }}\right)$ were obtained by breeding $F k b p 5^{\mathrm{Frt} / \text { Frt }}$ mice to Deleter-Flpe mice ${ }^{39}$. Finally, mice lacking Fkbp5 in PVN neurons ( $F k b p 5^{\mathrm{PVN}-/-}$ ) were obtained by breeding $F k b p 5^{\text {lox/lox }}$ mice to Sim1-Cre mice ${ }^{40}$. Genotyping details are available upon request.

Viral overexpression and rescue of Fkbp5. For overexpression and rescue experiments, stereotactic injections were performed as described previously ${ }^{41}$. We used an adeno-associated bicistronic AAV1/2 vector for the overexpression and rescue studies. In the overexpression experiments, the vector contained a CAG-HA-tagged-FKBP51-WPRE-BGH-polyA expression cassette (containing the coding sequence of human Fkbp51 NCBI CCDS ID CCDS4808.1). The same vector construct without expression of Fkbp5 (CAG-Null/Empty-WPRE-BGH-polyA) was used as a control. Virus production, amplification, and purification were performed by GeneDetect. For the rescue experiment, a viral vector containing a flippase expressing cassette (AAV2-eSYNeGFP-T2A-FLPo, Vector Biolabs; VB1093) was used to induce endogenous $F k b p 5$ expression in $F k b p 5^{\mathrm{FRT} / \mathrm{FRT}}$ mice. Control animals were injected with a control virus (AAV2-eSYN-eGFP; Vector Biolabs; VB1107). For both experiments, mice were anesthetized with isoflurane, and $0.2 \mu \mathrm{l}$ of the above-mentioned viruses (titers: $1.6 \times 10^{12-13}$ genomic particles $/ \mathrm{ml}$ ) were bilaterally injected in the PVN at $0.05 \mu \mathrm{l} / \mathrm{min}$ by glass capillaries with tip resistance of $2-4 \mathrm{M} \Omega$ in a stereotactic apparatus. The following coordinates were used: $-0.45 \mathrm{~mm}$ anterior to bregma, $0.3 \mathrm{~mm}$ lateral from midline, and $4.8 \mathrm{~mm}$ below the surface of the skull, targeting the PVN. After surgery, mice were treated for $3 \mathrm{~d}$ with 
Metacam via i.p. injections and were housed without any experiments for 3-4 weeks for total recovery. Successful overexpression and reinstatement of $F k b p 5$ was verified by ISH.

Acute stress paradigm. For acute stress, mice were placed in a 50 $\mathrm{ml}$ falcon tube with 2 holes at the top and the lid to provide enough oxygen and space for tail movement. On the experimental day, each animal was placed in the $50 \mathrm{ml}$ falcon for 15 minutes in their individual home cage. After 15 minutes, animals were removed from the tube and the first blood sample was collected by tail cut. Until the following tail cuts at 30, 60 and 90 minutes after stress onset, the animals remained in their home cage to recover. Basal CORT levels (morning CORT) were collected one week prior the acute stress paradigm at $8 \mathrm{am}$.

Combined Dex/CRH test. To investigate HPA axis function we performed a combined Dex/CRH test as described previously ${ }^{8}$. On the experimental day, mice were injected with a low dose dexamethasone $(0.05 \mathrm{mg} / \mathrm{kg}$, Dex-Ratiopharm, 7633932) via i.p. injections at 9 am in the morning. 6 hours after Dex injection, a blood sample was collected via tail cut (after Dex value), followed by an injection of $\mathrm{CRH}(0.15 \mathrm{mg} / \mathrm{kg}$, CRH Ferrin Amp). 30 min after $\mathrm{CRH}$ injection, another blood sample was obtained (after $\mathrm{CRH}$ value). All samples from the acute stress experiments and the Dex/CRH test were collected in $1.5 \mathrm{ml}$ EDTA-coated microcentrifuge tubes (Sarstedt, Germany). All blood samples were kept on ice and centrifuged for $15 \mathrm{~min}$ at $8000 \mathrm{rpm}$ and $4^{\circ} \mathrm{C}$. Plasma samples were transferred to a new, labeled microcentrifuge tubes and stored at $-20{ }^{\circ} \mathrm{C}$ until further processing.

Sampling procedure. At the day of sacrifice, animals were deeply anesthetized with isoflurane and sacrificed by decapitation. Trunk blood was collected in labeled $1.5 \mathrm{ml}$ EDTA-coated microcentrifuge tubes (Sarstedt, Germany) and kept on ice until centrifugation. After centrifugation $\left(4^{\circ} \mathrm{C}, 8000 \mathrm{rpm}\right.$ for $\left.1 \mathrm{~min}\right)$ the plasma was removed and transferred to new, labeled tubes and stored at $-20^{\circ} \mathrm{C}$ until hormone quantification. For mRNA analysis, brains were removed, snap-frozen in isopentane at $-40^{\circ} \mathrm{C}$ and stored at $-80^{\circ} \mathrm{C}$ for $1 \mathrm{SH}$. For protein analysis, brains were removed and placed inside a brain matrix with the hypothalamus facing upwards (spacing $1 \mathrm{~mm}$, World Precision Instruments, Berlin, Germany). Starting from the middle of the chiasma opticum, a $1 \mathrm{~mm}$ thick brain slice was removed. The PVN was further isolated by cutting the slice on both sides of the PVN along the formices (parallel to the $3^{\text {rd }}$ ventricle) as a landmark and a horizontal cut between the reuniens and the thalamic nucleus. Finally, the slice containing the $3^{\text {rd }}$ ventricle was bisected, and the distal part discarded. The remaining part (containing the PVN) was immediately shock frozen and stored at $-80^{\circ} \mathrm{C}$ until protein analysis ${ }^{42}$. The adrenals and thymus glands were dissected from fat and weighed.

Hormone assessment. CORT and ACTH concentrations were determined by radioimmunoassay using a corticosterone double antibody ${ }^{125}$ I RIA kit (sensitivity: $12.5 \mathrm{ng} / \mathrm{ml}$, MP Biomedicals Inc) and adrenocorticotropic double antibody hormone ${ }^{125}$ I RIA kit (sensitivity: $10 \mathrm{pg} / \mathrm{ml}, \mathrm{MP}$ Biomedicals $\mathrm{Inc}$ ) and were used following the manufacturers' instructions. Radioactivity of the pellet was measured with a gamma counter (Packard Cobra II Auto Gamma; Perkin-Elmer). Final CORT and ACTH levels were derived from the standard curve.

In-situ hybridization. ISH was used to analyze mRNA expression of the major stress markers, Fkbp5, Gr, Crh, and Avp. Therefore, frozen brains were sectioned at $-20^{\circ} \mathrm{C}$ in a cryostat microtome at $20 \mu \mathrm{m}$, thaw mounted on Super Frost Plus slides, dried and stored at $-80{ }^{\circ} \mathrm{C}$. The ISH using ${ }^{35} \mathrm{~S}$ UTP labeled ribonucleotide probes was performed as described previously ${ }^{21,29}$. All primer details are available upon request. Briefly, sections were fixed in $4 \%$ paraformaldehyde and acetylated in $0.25 \%$ acetic anhydride in $0.1 \mathrm{M}$ triethanolamine $/ \mathrm{HCl}$. Subsequently, brain sections were dehydrated in increasing concentrations of ethanol. The antisense CRNA probes were transcribed from a linearized plasmid. Tissue sections were saturated with $100 \mu \mathrm{l}$ of hybridization buffer containing approximately $1.5 \times 10^{6} \mathrm{cpm}{ }^{35} \mathrm{~S}$ labeled riboprobe. Brain sections were coverslipped and incubated overnight at $55^{\circ} \mathrm{C}$. On the next day, the sections were rinsed in $2 \times$ SSC (standard saline citrate), treated with RNAse A $(20 \mathrm{mg} / \mathrm{l})$. After several washing steps with $\mathrm{SSC}$ solutions at room temperature, the sections were washed in $0.1 \times$ SSC for $1 \mathrm{~h}$ at $65^{\circ} \mathrm{C}$ and dehydrated through increasing concentrations of ethanol. Finally, the slides were air-dried and exposed to Kodak Biomax MR films (Eastman Kodak Co., Rochester, NY) and developed. Autoradiographs were digitized, and expression was determined by optical densitometry utilizing the freely available NIH ImageJ software. The mean of four measurements of two different brain slices was calculated for each animal. The data were analyzed blindly, always subtracting the background signal of a nearby structure not expressing the gene of interest from the measurements. For Fkbp5, slides were dipped in Kodak NTB2 emulsion (Eastman Kodak Co., Rochester, NY) and exposed at 4 ${ }^{\circ} \mathrm{C}$ for three weeks for better visibility of the viral spread and genetic deletion. Slides were developed and examined with a light microscope with darkfield condensers to show mRNA expression.

RNAscope analysis and cell counting. For the RNAscope experiments, $\mathrm{C} 57 \mathrm{BL} / 6 \mathrm{~J}$ male mice were obtained from The Jackson Laboratory (Bar Harbour, ME, USA). All procedures conformed to National Institutes of Health guidelines and were approved by McLean Hospital Institutional Animal Care and Use Committee. Mice were housed in a temperature-controlled colony in the animal facilities of McLean Hospital in Belmont, MA, USA. All mice were group-housed and maintained on a 12:12 h light/dark cycle (lights on at 07:00 am). Food and water were available ad libitum unless specified otherwise. Mice were 12 weeks at the time of tissue collection. Animals were allowed to acclimate to the room for 1 week before the beginning of the experiment. During the experiment mice were either left undisturbed (ctrl) or subjected to $14 \mathrm{hrs}$ (overnight) of food deprivation (FD) prior to sacrifice. During the stress procedure, animals were kept in their home cages and had free access to tap water. All mice were sacrificed by decapitation in the morning (08:00 to 08:30 am) following quick anesthesia by isoflurane. Brains were removed, snap-frozen in isopentane at - 
$40^{\circ} \mathrm{C}$, and stored at $-80^{\circ} \mathrm{C}$. Frozen brains were sectioned in the coronal plane at $-20^{\circ} \mathrm{C}$ in a cryostat microtome at $18 \mu \mathrm{m}$, mounted on Super Frost Plus slides, and stored at $-80^{\circ} \mathrm{C}$. The RNA Scope Fluorescent Multiplex Reagent kit (cat. no. 320850, Advanced Cell Diagnostics, Newark, CA, USA) was used for mRNA staining. Probes used for staining were; $\mathrm{mm}-\mathrm{Avp}-\mathrm{C} 3, \mathrm{~mm}-\mathrm{Crh}-\mathrm{C} 3$, mm-Fkbp5-C2, mm-Oxt-C3, mm-Sst-C3, and mm-Trh-C3. The staining procedure was performed according to manufacturer's specifications. Briefly, sections were fixed in $4 \%$ paraformaldehyde for $15 \mathrm{~min}$ at $4^{\circ} \mathrm{C}$. Subsequently, brain sections were dehydrated in increasing concentrations of ethanol. Next, tissue sections were incubated with protease IV for $30 \mathrm{~min}$ at room temperature. Probes (probe diluent (cat. no. 300041 used instead of (1-probe), Fkbp5-C2 and one of the above C3-probes) were hybridized for $2 \mathrm{hrs}$ at $40^{\circ} \mathrm{C}$ followed by 4 hybridization steps of the amplification reagents 1 to 4 . Next, sections were counterstained with DAPI, cover-slipped and stored at $4^{\circ} \mathrm{C}$ until image acquisition. Images of the PVN (left and right side) were acquired by an experimenter blinded to the condition of the animals. Sixteen-bit images of each section were acquired on a Leica SP8 confocal microscope using a 40x objective ( $n=3$ animals per marker and condition). For every individual marker, all images were acquired using identical settings for laser power, detector gain, and amplifier offset. Images of both sides were acquired as a z-stack of 3 steps of 1.0 $\mu \mathrm{m}$ each. Fkbp5 mRNA expression and co-expression was analyzed using ImageJ with the experimenter blinded to condition of the animals. Fkbp5 mRNA was counted manually and each cell containing 1 mRNA dot was counted as positive.

\section{Single-cell sequencing.}

Tissue dissociation. Mice were anesthetized lethally using isoflurane and perfused with cold PBS. Brains were quickly dissected, transferred to ice-cold oxygenated artificial cerebral spinal fluid (aCSF), and kept in the same solution during dissection. Sectioning was performed using a $0.5 \mathrm{~mm}$ stainless steel adult mouse brain matrice (Kent Scientific) and a Personna Double Edge Prep Razor Blade. A slide (approximately $-0.58 \mathrm{~mm}$ Bregma to $-1.22 \mathrm{~mm}$ Bregma) was obtained from each brain and the extended PVN was manually dissected under the microscope. The PVN from five different mice was pooled and dissociated using the Papain dissociation system (Worthington) following the manufacturer's instructions. All solutions were oxygenated with a mixture of $5 \% \mathrm{CO}_{2}$ in $\mathrm{O}_{2}$. After this, the cell suspension was filtered with $30 \mu \mathrm{m}$ filter (Partec) and kept in cold and oxygenated aCSF.

Cell capture, library preparation, and high-throughput sequencing. Cell suspensions of PVN with approximately 1.000 .000 cells $/ \mu \mathrm{L}$ were used. Cells were loaded onto two lanes of a 10X Genomics Chromium chip per factory recommendations. Reverse transcription and library preparation was performed using the 10X Genomics Single Cell v2.0 kit following the $10 \mathrm{X}$ Genomics protocol. The library molar concentration and fragment length was quantified by qPCR using KAPA Library Quant (Kapa Biosystems) and Bioanalyzer (Agilent high sensitivity DNA kit), respectively. The library was sequenced on a single lane of an Illumina HiSeq4000 system generating $100 \mathrm{bp}$ paired-end reads at a depth of $\sim 340$ million reads per sample.

Quality control and identification of cell clusters. Pre-processing of the data was done using the 10X Genomics Cell Ranger software version 2.1.1 in default mode. The 10X Genomics supplied reference data for the $\mathrm{mm} 10$ assembly and corresponding gene annotation was used for alignment and quantification. All further analysis was performed using SCANPY version $1.3 .7^{43}$. A total of 5.113 cells were included after filtering gene counts $(<750$ and $>6.000)$, UMI counts $(>25.000)$ and fraction of mitochondrial counts $(>0.2)$. Combat ${ }^{44}$ was used to remove chromium channel as batch effect from normalized data. The 4.000 most variable genes were subsequently used as input for Louvain cluster detection. Cell types were determined using a combination of marker genes identified from the literature and gene ontology for cell types using the web-based tool: mousebrain.org (http://mousebrain.org/genesearch.html).

Western blot analysis. Protein extracts were obtained by lysing cells (in RIPA buffer (150 mM NaCl, 1\% IGEPAL CA-630, $0.5 \%$ Sodium deoxycholate, $0.1 \%$ SDS 50mM Tris (pH8.0)) freshly supplemented with protease inhibitor (Merck Millipore, Darmstadt, Germany), benzonase (Merck Millipore), 5 mM DTT (Sigma Aldrich, Munich, Germany), and phosphatase inhibitor (Roche, Penzberg, Germany) cocktail. Proteins were separated by SDS-PAGE and electro-transferred onto nitrocellulose membranes. Blots were placed in Tris-buffered saline, supplemented with $0.05 \%$ Tween (Sigma Aldrich) and 5\% non-fat milk for $1 \mathrm{~h}$ at room temperature and then incubated with primary antibody (diluted in TBS/0.05\% Tween) overnight at $4{ }^{\circ} \mathrm{C}$. The following primary antibodies were used: Actin (1:5000, Santa Cruz Biotechnologies, sc-1616), GR (1:1000, Cell Signaling Technology, \#3660), p-GR Ser211 (1:500, Sigma, SAB4503820), pGR Ser226 (1:1000, Sigma, SAB4503874), p-GR 203 (1:500, Sigma, SAB4504585), FKBP51 (1:1000, Bethyl, A301-430A).

Subsequently, blots were washed and probed with the respective horseradish peroxidase or fluorophore-conjugated secondary antibody for $1 \mathrm{~h}$ at room temperature. The immunoreactive bands were visualized either using $\mathrm{ECL}$ detection reagent (Millipore, Billerica, MA, USA) or directly by excitation of the respective fluorophore. Determination of the band intensities were performed with BioRad, ChemiDoc MP. For quantification of phosphorylated GR, the intensity of phosphor$G R$ was always referred to the signal intensity of the corresponding total GR.

Chromatin preparation for chromatin immunoprecipitation (ChIP) analysis. The GR ChIP was performed as previously described $^{26}$. We added $1 \mathrm{mM}$ AEBSF or $0.1 \mathrm{mM} \mathrm{PMSF}, 5 \mathrm{mM} \mathrm{Na}{ }^{+}-$ Butyrate (NaBut), and PhosSTOP phosphatase inhibitor cocktail tablets (1 per $10 \mathrm{ml}$; Roche, Burgess Hill, UK) to all solutions unless otherwise stated. Briefly, hypothalamus tissues from four mice were cross-linked for $10 \mathrm{~min}$ in $1 \%$ formaldehyde in PBS. Crosslinking was terminated by adding glycine $(5 \mathrm{~min}$, final concentration $200 \mu \mathrm{M}$ ) and centrifuged (5 min, $6000 \mathrm{~g}, 4^{\circ} \mathrm{C}$ ). Pellets were washed three times with ice-cold PBS. Next, the 
pellets were re-suspended in ice-cold Lysis Buffer [50 mM Tris$\mathrm{HCl} \mathrm{pH} \mathrm{8,} 150 \mathrm{mM} \mathrm{NaCl}, 5 \mathrm{mM}$ EDTA pH 8.0, 0.5\% v/v Igepal, $0.5 \%$ Na-deoxycholate, $1 \%$ SDS, $5 \mathrm{mM}$ NaBut, $2 \mathrm{mM} \mathrm{AEBSF}, 1 \mathrm{mM}$ Na3VO4, Complete ultra EDTA-free protease inhibitor tablets and PhosSTOP phosphatase inhibitor cocktail tablet (both 1 per $10 \mathrm{ml}$, Roche, Burgess Hill, UK)] and rotated for $15 \mathrm{~min}$ at $4^{\circ} \mathrm{C}$. Samples were aliquoted, sonicated (high power; $2 \times 10$ cycles; 30 s ON, $60 \mathrm{~s}$ OFF) using a water-cooled $\left(4^{\circ} \mathrm{C}\right)$ Bioruptor Pico (Diagenode, Liège, Belgium) and centrifuged (10 min, 20,000 g, $4^{\circ} \mathrm{C}$ ). Supernatants (containing the sheared chromatin) were recombined and re-aliquoted into fresh tubes for subsequent ChIP analysis and for assessment of Input DNA (i.e., the starting material). Chromatin was sonicated to a length of approximately 500 base pairs.

For ChIP analysis, aliquots of chromatin were diluted 10-times in ice-cold dilution buffer [50 mM Tris- $\mathrm{HCl} \mathrm{pH} 8.0,150 \mathrm{mM} \mathrm{NaCl}, 5$ mM EDTA pH 8.0, 1\% v/v Triton, 0.1\% Na-deoxycholate $5 \mathrm{mM}$ NaBut, 1 mM AEBSF, Complete Ultra EDTA-free protease inhibitor tablets and PhosSTOP phosphatase inhibitor cocktail tablet (both 1 per $10 \mathrm{ml}$, Roche)]. $10 \mu \mathrm{l}$ of $\mathrm{GR}$ antibody (ProteinTech, USA) was added to each sample and tubes were rotated overnight at $4^{\circ} \mathrm{C}$. Protein A-coated Dynabeads ${ }^{\circledR}$ (Life Technologies) were washed once in ice-cold $0.5 \% \mathrm{BSA} / \mathrm{PBS}$ before blocking overnight at $4^{\circ} \mathrm{C}$. Pre-blocked beads were washed once in ice-cold dilution buffer, re-suspended in the antibody:chromatin mix, and allowed to incubate for $3 \mathrm{~h}$ at $4^{\circ} \mathrm{C}$ to allow binding of beads to antibody:chromatin complexes. After $3 \mathrm{~h}$, the samples were placed in a magnetic stand to allow the beads (with the Bound fraction bound) to separate from the liquid 'Unbound' fraction. Beads carrying the Bound chromatin were washed 3 times with ice-cold RIPA buffer [10 $\mathrm{mM}$ Tris- $\mathrm{HCl}$ pH 7.5, 1 mM EDTA pH 7.5, 0.1\% SDS, 0.5 mM EGTA, 1\% Triton, $0.1 \% \mathrm{Na}$-Deoxycholate, $140 \mathrm{mM} \mathrm{NaCl}+$ inhibitors] and washed twice with ice-cold Tris-EDTA buffer. Bound DNA was eluted in two steps at room temperature; first with $200 \mu$ l Elution buffer 1 (10 mM Tris- $\mathrm{HCl} \mathrm{pH} \mathrm{7.4,} 50 \mathrm{mM} \mathrm{NaCl}, 1.5 \% \mathrm{SDS}$ ) and second with $100 \mu$ l Elution buffer $2(10 \mathrm{mM}$ Tris- $\mathrm{HCl} \mathrm{pH} 7.4,50 \mathrm{mM} \mathrm{NaCl}$, $0.5 \%$ SDS). Crosslinks were reversed by addition of $\mathrm{NaCl}$ (final concentration $200 \mathrm{mM}$ ) and overnight incubation at $65^{\circ} \mathrm{C}$. The next day, samples were incubated first with RNase A $(60 \mu \mathrm{g} / \mathrm{ml}$, $\left.37^{\circ} \mathrm{C}, 1 \mathrm{~h}\right)$, followed by incubation with proteinase $\mathrm{K}(250 \mathrm{\mu g} / \mathrm{ml}$, $37^{\circ} \mathrm{C}, 3.5 \mathrm{~h}$ ). DNA was purified using a QIAquick PCR purification kit (Qiagen) as per manufacturer's instructions. Input samples were incubated overnight at $65^{\circ} \mathrm{C}$ with $200 \mathrm{mM} \mathrm{NaCl}$ to reverse crosslinks, incubated with RNase $A$ and proteinase $K$ (overnight), and DNA was purified using a Qiagen PCR purification kit. All samples (Bounds and Inputs) were diluted to a standardized concentration with nuclease free water and analyzed by qPCR as described below using primers/probes (Forward: 5'TGTCAATGGACAAGTCATAAGAAACC; Reverse: 5' GAATCTCACATCCAATTATATCAACAGAT; Probe: 5' TTCCATTTTCGGGCTCGTTGACGTC. Binding of GR was expressed as a percentage of input DNA, i.e., \% Input, which is a measure of the enrichment of steroid receptor bound to specific genomic sequences.
qPCR analysis: Mastermix for qPCR was prepared containing 900 $\mathrm{nM}$ forward and reverse primers, $200 \mathrm{nM}$ probe, 1X TaqMan fast mastermix (Life Technologies, Paisley, UK) and made up to volume with nuclease-free water. Primers and dual-labeled probe with 6-FAM as the fluorescent dye and TAMRA as the quencher were designed using Primer Express software (Version 3.0.1, Life Technologies). Standard curves were performed for each primer pair and the qPCR efficiency was calculated using the equation: $E=((10-1 /$ slope $)-1) \times 100$ (where $E$ is qPCR efficiency and the slope is the gradient of the standard curve). Only primer pairs with efficiencies greater than $90 \%$ were used. Quantitative PCR was performed using a StepOne Plus machine (Life Technologies, Paisley, UK). Taq enzymes were activated at $95^{\circ} \mathrm{C}$ for $20 \mathrm{~s}$, then 40 cycles of $95^{\circ} \mathrm{C}(1 \mathrm{~s})$ to $60^{\circ} \mathrm{C}(20 \mathrm{~s})$ were performed to amplify samples.

\section{Statistical analysis.}

The data presented are shown as means \pm SEM and samples sizes are indicated in the figure legends. All data were analyzed by the commercially available software SPSS 17.0 and GraphPad 8.0. When two groups were compared, the unpaired student's $t$-test was applied. If data were not normally distributed the nonparametric Mann-Whitney test (MW-test) was used. For four group comparisons, two-way analysis of variance (ANOVA) was performed, followed by posthoc test, as appropriate. $P$ values of less than 0.05 were considered statistically significant.

\section{Acknowledgments}

The authors thank Claudia Kühne, Mira Jakovcevski, Daniela Harbich and Bianca Schmid (Max Planck Institute of Psychiatry, Munich, Germany) for their excellent technical assistant and support. We thank Stefanie Unkmeir, Sabrina Bauer and the scientific core unit Genetically Engineered Mouse Models for genotyping support. This work was supported by the "OptiMD" grant of the Federal Ministry of Education and Research (01EE1401D; M.V.S.), the BioM M4 award "PROCERA" of the Bavarian State Ministry (M.V.S.) and by a NARSAD Young Investigator Grant from the Brain \& Behavior Research Foundation (J.H.).

\section{Author contributions}

A.S.H, and M.V.S.: Conceived the project and designed the experiments. J.M.D.: Provided scientific expertise for establishing Fkbp5 mouse lines. A.S.H and L.M.B. managed the mouse lines and genotyping. A.S.H., M.L.P., L.R., and L.M.B. performed animal experiments and surgeries. R.S.: Performed CORT and ACTH hormone assays and analysis. J.P.L., S.R., and E.B.: Performed single cell sequencing experiments and analysis. J.M.H.M.R, and H.M.G.: Performed and analyzed GR-CHIP experiments. A.S.H, J.H., and C.E.: Performed and designed RNAscope experiments and manual counting of cells. N.C.G, and K.H.: Performed protein analysis. K.J.R. and A.C.: Supervised and revised the manuscript. A.S.H.: Wrote the initial version of the manuscript. M.V.S.: Supervised the research and all authors revised the manuscript.

\section{Competing interests}

The authors declare no competing interests. 


\section{References}

1. De Kloet, E. R., Joëls, M. \& Holsboer, F. Stress and the brain: From adaptation to disease. Nat. Rev. Neurosci. 6, 463-475 (2005).

2. Sinars, C. R. et al. Structure of the large FK506-binding protein FKBP51, an Hsp90-binding protein and a component of steroid receptor complexes. Proc.NatI.Acad.Sci.U.S.A 100, 868-873 (2003).

3. Wochnik, G. M. et al. FK506-binding proteins 51 and 52 differentially regulate dynein interaction and nuclear translocation of the glucocorticoid receptor in mammalian cells. J. Biol. Chem. 280, 4609-16 (2005).

4. Scammell, J. G., Denny, W. B., Valentine, D. L. \& Smith, D. F. Overexpression of the $\{F K\} 506$-binding immunophilin $\{F K B P\} 51$ is the common cause of glucocorticoid resistance in three $\{\mathrm{New}\}$ World primates. Gen.Comp Endocrinol. 124, 152-165 (2001).

5. Binder, E. B. et al. Association of FKBP5 polymorphisms and childhood abuse with risk of posttraumatic stress disorder symptoms in adults. JAMA 299, 1291-1305 (2008).

6. Denny, W. B., Valentine, D. L., Reynolds, P. D., Smith, D. F. \& Scammell, J. G. Squirrel monkey immunophilin $\{F K B P\} 51$ is a potent inhibitor of glucocorticoid receptor binding. Endocrinology 141, 4107-4113 (2000).

7. Ising, M. et al. Polymorphisms in the $\{F K B P\} 5$ gene region modulate recovery from psychosocial stress in healthy controls. Eur.J.Neurosci. 28, 389-398 (2008).

8. Touma, C. et al. FK506 binding protein 5 shapes stress responsiveness: Modulation of neuroendocrine reactivity and coping behavior. Biol. Psychiatry 70, 928936 (2011).

9. Westberry, J. M., Sadosky, P. W., Hubler, T. R., Gross, K. L. \& Scammell, J. G. Glucocorticoid resistance in squirrel monkeys results from a combination of a transcriptionally incompetent glucocorticoid receptor and overexpression of the glucocorticoid receptor cochaperone $\{F K B P\} 51$. J.Steroid Biochem. 100, 34-41 (2006).

10. Scharf, S. H., Liebl, C., Binder, E. B., Schmidt, M. V. \& Müller, M. B. Expression and regulation of the Fkbp5 gene in the adult mouse brain. PLoS One 6, 1-10 (2011).

11. Zannas, A. S. \& Binder, E. B. Gene-environment interactions at the FKBP5 locus: sensitive periods, mechanisms and pleiotropism. Genes, Brain Behav. 13, 25-37 (2014).

12. Matosin, N., Halldorsdottir, T. \& Binder, E. B. Understanding the Molecular Mechanisms Underpinning Gene by Environment Interactions in Psychiatric Disorders: The FKBP5 Model. (2018). doi:10.1016/j.biopsych.2018.01.021

13. Binder, E. B. et al. Polymorphisms in FKBP5 are associated with increased recurrence of depressive episodes and rapid response to antidepressant treatment. Nat. Genet. 36, 1319-1325 (2004).

14. Klengel, T. et al. Allele-specific FKBP5 DNA demethylation mediates gene-childhood trauma interactions. Nat. Neurosci. 16, 33-41 (2013).

15. Gassen, N. C. et al. Association of FKBP51 with Priming of Autophagy Pathways and Mediation of Antidepressant Treatment Response: Evidence in Cells, Mice, and Humans. PLoS Med. 11, e1001755 (2014).

16. Hartmann, J. et al. Pharmacological Inhibition of the Psychiatric Risk Factor FKBP51 Has Anxiolytic Properties. J.Neurosci. 35, 9007-9016 (2015).

17. Ising, M. \& Holsboer, F. Genetics of stress response and stress-related disorders. Dialogues Clin. Neurosci. 8, 433-44 (2006).

18. Wagner, K. V. et al. Differences in FKBP51 regulation following chronic social defeat stress correlate with individual stress sensitivity: Influence of paroxetine treatment. Neuropsychopharmacology 37, 2797-2808 (2012).

19. Nestler, E. J. et al. Neurobiology of depression. Neuron 34, 13-25 (2002).

20. Tsigos, C. \& Chrousos, G. P. Hypothalamic-pituitaryadrenal axis, neuroendocrine factors and stress. J. Psychosom. Res. 53, 865-871 (2002).

21. Hartmann, J. et al. The involvement of FK506-binding protein 51 (FKBP5) in the behavioral and neuroendocrine effects of chronic social defeat stress. Neuropharmacology 62, 332-339 (2012).

22. Galliher-Beckley, A. J. \& Cidlowski, J. A. Emerging roles of glucocorticoid receptor phosphorylation in modulating glucocorticoid hormone action in health and disease. IUBMB Life 61, 979-986 (2009).

23. Wang, Z., Frederick, J. \& Garabedian, M. J. Deciphering the phosphorylation \&quot;code\&quot; of the glucocorticoid receptor in vivo. J. Biol. Chem. 277, 26573-80 (2002).

24. Luecken, M. D. \& Theis, F. J. Current best practices in single-cell RNA-seq analysis: a tutorial. Mol. Syst. Biol. (2019). doi:10.15252/msb.20188746

25. Hoeijmakers, L. et al. Depletion of FKBP51 in female mice shapes HPA axis activity. PLoS One (2014). doi:10.1371/journal.pone.0095796

26. Mifsud, K. R. \& Reul, J. M. H. M. Acute stress enhances heterodimerization and binding of corticosteroid receptors at glucocorticoid target genes in the hippocampus. Proc. Natl. Acad. Sci. U. S. A. 113, 1133611341 (2016).

27. Sabbagh, J. J. et al. Age-associated epigenetic upregulation of the FKBP5 gene selectively impairs stress resiliency. PLoS One 9, e107241 (2014).

28. O'Leary, J. C. et al. A new anti-depressive strategy for the elderly: Ablation of FKBP5/FKBP51. PLoS One 6, (2011).

29. Schmidt, M. V. et al. Persistent neuroendocrine and behavioral effects of a novel, etiologically relevant mouse paradigm for chronic social stress during adolescence. Psychoneuroendocrinology 32, 417-429 (2007).

30. Klein, F. et al. Prolonged increase of corticosterone 
secretion by chronic social stress does not necessarily impair immune funnctions. Life Sci. 50, 723-731 (1992).

31. Laryea, G., Arnett, M. \& Muglia, L. J. Ontogeny of hypothalamic glucocorticoid receptor-mediated inhibition of the hypothalamic-pituitary-adrenal axis in mice. Stress

(2015). doi:10.3109/10253890.2015.1046832

32. De Kloet, E. R. Hormones and the stressed brain. Ann. N. Y. Acad. Sci. 1018, 1-15 (2004).

33. Blind, R. D. \& Garabedian, M. J. Differential recruitment of glucocorticoid receptor phospho-isoforms to glucocorticoid-induced genes. J. Steroid Biochem. Mol. Biol. 109, 150-157 (2008).

34. Wang, Z., Frederick, J. \& Garabedian, M. J. Deciphering the phosphorylation 'code' of the glucocorticoid receptor in vivo. J. Biol. Chem. 277, 26573-26580 (2002).

35. Krstic, M. D., Rogatsky, I., Yamamoto, K. R. \& Garabedian, M. J. Mitogen-activated and cyclindependent protein kinases selectively and differentially modulate transcriptional enhancement by the glucocorticoid receptor. Mol. Cell. Biol. 17, 3947-54 (1997).

36. Kino, T. et al. Cyclin-Dependent Kinase 5 Differentially Regulates the Transcriptional Activity of the Glucocorticoid Receptor through Phosphorylation: Clinical Implications for the Nervous System Response to Glucocorticoids and Stress. Mol. Endocrinol. 21, 15521568 (2007).

37. Gassen, N. C. et al. FKBP51 inhibits GSK3 3 and augments the effects of distinct psychotropic medications. Mol. Psychiatry 21, 277-89 (2016).

38. Scharf, S. H. \& Schmidt, M. V. Animal models of stress vulnerability and resilience in translational research. Curr. Psychiatry Rep. 14, 159-165 (2012).

39. Rodríguez, C. I. et al. High-efficiency deleter mice show that FLPe is an alternative to Cre- IoxP. Nature Genetics (2000). doi:10.1038/75973

40. Balthasar, N. et al. Divergence of melanocortin pathways in the control of food intake and energy expenditure. Cell 123, 493-505 (2005).

41. Schmidt, M. V. et al. Tumor suppressor down-regulated in renal cell carcinoma 1 (DRR1) is a stress-induced actin bundling factor that modulates synaptic efficacy and cognition. Proc. Natl. Acad. Sci. 108, 17213-17218 (2011).

42. Jakovcevski, M., Schachner, M. \& Morellini, F. Susceptibility to the long-term anxiogenic effects of an acute stressor is mediated by the activation of the glucocorticoid receptors. Neuropharmacology 61, 12971305 (2011).

43. F. Alexander Wolf, P. A. and F. J. T. SCANPY: Large-scale single cell data analysis. Genome Biol. 19, 2926-2934 (2017).

44. Johnson, W. E., Li, C. \& Rabinovic, A. Adjusting batch effects in microarray expression data using empirical Bayes methods. Biostatistics 8, 118-127 (2007). 


\section{Supplementary Information}

Supplementary Figure 1

\section{A Basal corticosterone level}

B

Basal

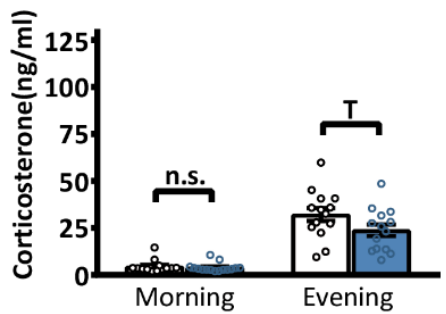

E Fkbp5 protein validation
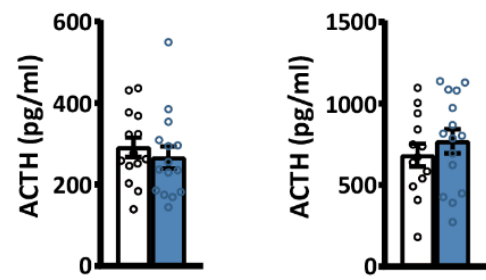

D mRNA analysis

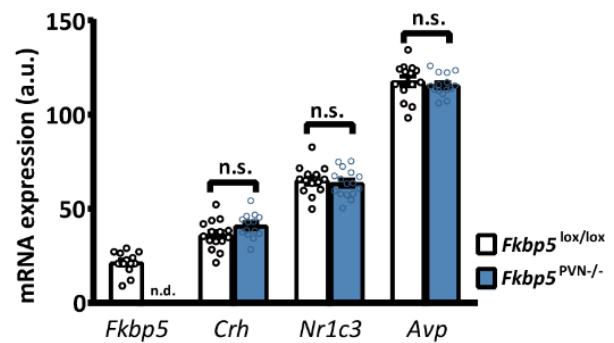

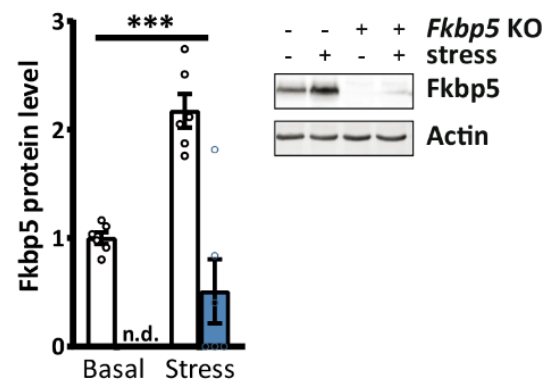

Suppl. Figure 1: Corticosterone and ACTH levels of $F k b p 5^{\mathrm{PVN}-/-}$ mice. Fkbp5 deletion in the PVN has no effect basal CORT levels $\left(F k b p 5^{\mathrm{PVN}-/-} \mathrm{n}=16 ; F k b p 5^{\text {lox/lox }} \mathrm{n}=15\right)(\mathbf{A})$. ACTH levels under basal $\left(F k b p 5^{\mathrm{PVN}-/-} \mathrm{n}=16 ; F k b p 5^{\text {lox/lox }} \mathrm{n}=15\right)$ (B) and 30 minutes after stress onset were unaltered $\left(F k b p 5^{\text {PVN-F }} \mathrm{n}=16 ; F k b p 5^{\text {lox/lox }} \mathrm{n}=15\right)$ (C). (D) mRNA changes of stress responsive genes within the PVN $\left(F k b p 5^{\mathrm{PVN}-/} \mathrm{n}=16 ; \mathrm{Fkbp}^{\mathrm{lox} / \mathrm{lox}} \mathrm{n}=15\right)$. (E) Fkbp5 protein levels were not detectable under basal conditions. All data are presented as mean \pm SEM and were analyzed with a student's t-test. $n . d$. = not detectable; n.s. $=$ not significant; $T=0.05<p<0.1$.

Supplementary Figure 2

\section{A Body Physiology}

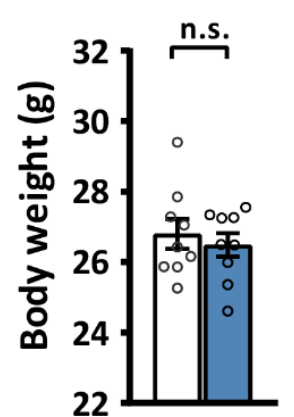

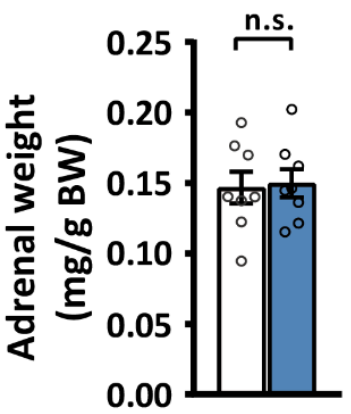

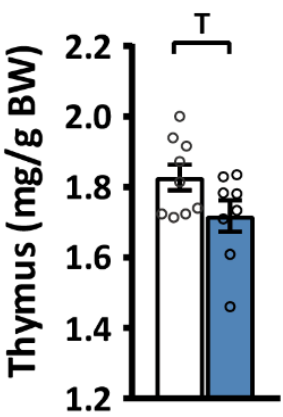

B Basal corticosterone levels

Morning

Evening

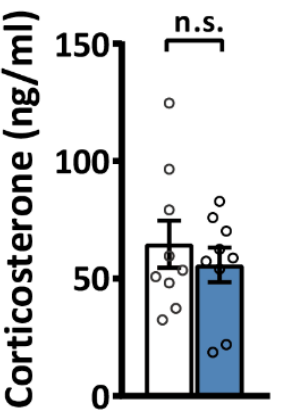

C Acute stress response

15 Minutes

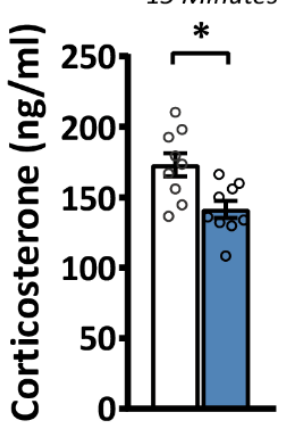

30 Minutes

60 Minutes
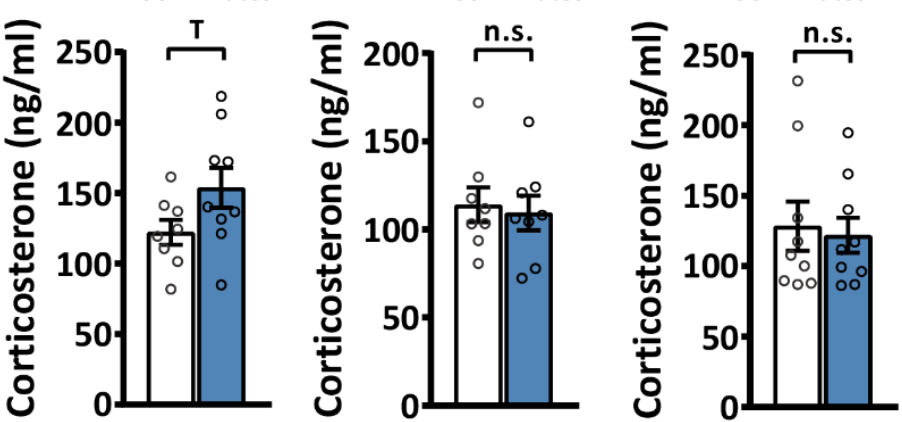

$\square$ Fkbp5 ${ }^{\text {lox/lox }}$
$\square$ Fkbp5

Suppl. Figure 2: Young mice with Fkbp5 deletion in the PVN. (A) Animals with an age of 10 weeks had no alterations in body physiology. (B) Morning and evening corticosterone levels were unchanged. (C) Fkbp5 ${ }^{\mathrm{PVN}-l_{-}}$had significant lower corticosterone 
bioRxiv preprint doi: https://doi.org/10.1101/824664; this version posted October 30, 2019. The copyright holder for this preprint (which was not certified by peer review) is the author/funder. All rights reserved. No reuse allowed without permission.

levels 15 minutes after stress onset. (Group size for A-C: $F k b p 5^{\mathrm{PVN}-/-} \mathrm{n}=9 ; F k b p 5^{\text {lox/lox }} \mathrm{n}=9$ ). All data are presented as mean \pm SEM and were analyzed with a student's t-test. n.s. = not significant; $T=0.05<p<0.1 ; *=p<0.05$.

Supplementary Figure 3

A Basal ACTH

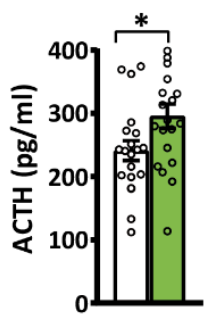

E Fkbp5 protein validation

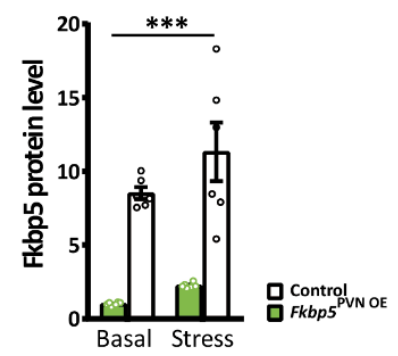

B 30 minutes $\mathrm{ACTH}$
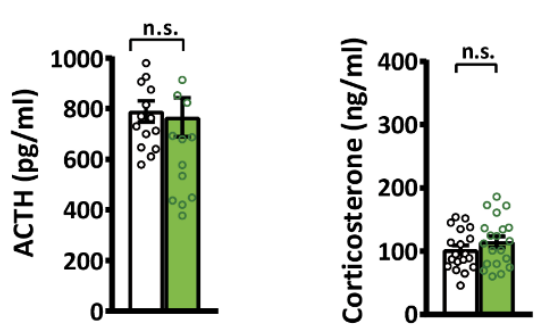

D mRNA analysis

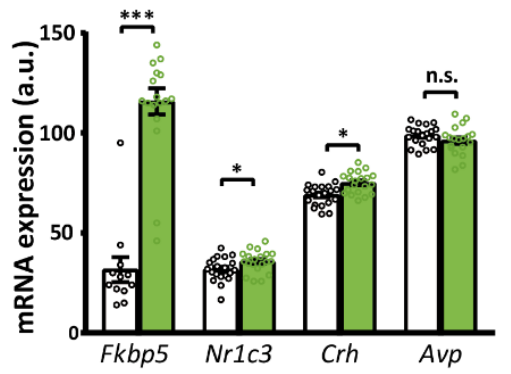

Suppl. Figure 3: Overexpression of Fkbp5 in the PVN affected ACTH and mRNA levels. (A-B) ACTH levels were significantly higher in $F k b p 5^{\mathrm{PVN} O E}$ mice under basal ( $\mathrm{n}=20$ vs. 20) and unchanged 30 minutes after stress ( $\mathrm{n}=12$ vs. $12=$ onset compared to their controls. (C) We did not detect any differences in corticosterone levels 90 minutes after stress onset $(n=20$ vs. 20). (D) Fkbp5 overexpression resulted in significant increase in mRNA levels of Fkbp5, N1c3 and Crh. Avp levels stayed unchanged ( $n=20$ vs. 20). (E) Viral overexpression resulted in a 4-fold Fkbp5 protein upregulation in the PVN ( $n=20$ vs. 20). All data are presented as mean \pm SEM and were analyzed with a student's t-test (A-D) or with a two way ANOVA (E). n.s. = not significant; $\mathrm{T}=0.05<\mathrm{p}<0.1 .^{*}=\mathrm{p}<0.05, * * *=p<0.001$.

Supplementary Figure 4

A Thymus weight

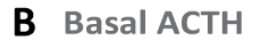

C Evening corticosterone
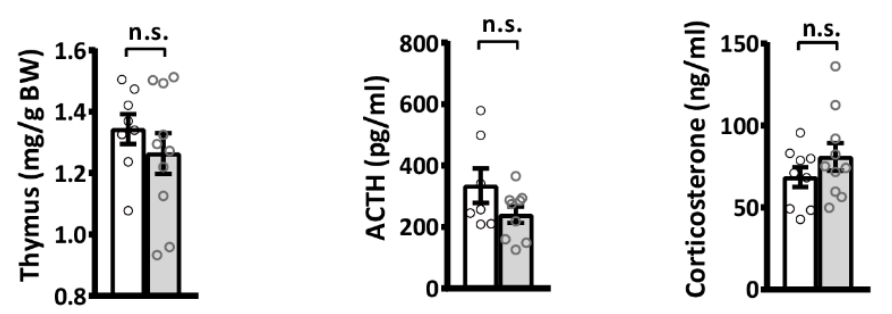

E mRNA analysis

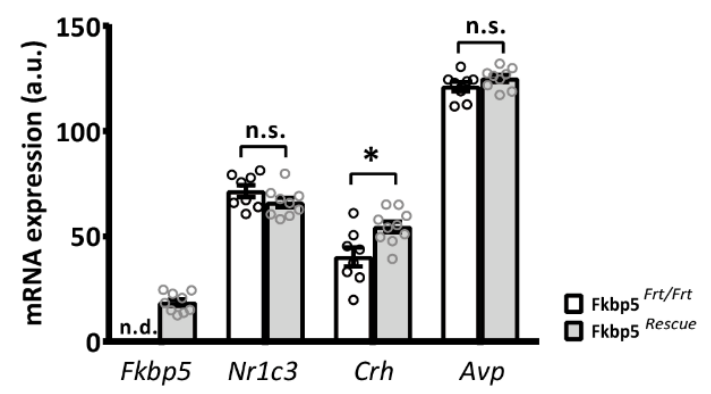

Suppl. Figure 4: Corticosterone and ACTH levels of Fkbp5 ${ }^{\text {Rescue }}$ mice. Fkbp5 reinstatement had no effect on thymus weights (A). Basal ACTH and evening corticosterone levels were unaltered (B \& C). (D) Rescue of endogenous Fkbp5 in global knockout animals had no significant effect on the Dex/CRH test and on stress responsive mRNA levels in the brain. (E) mRNA levels in $F k b p 5^{\text {Rescue }}$ animals compared to global knock-out littermates. Group sizes for A-E: $F k b p 5^{\text {Rescue }} \mathrm{n}=10 ; F k b p 5^{\text {Frt/Frt }} \mathrm{n}=9$ ) All data are presented as mean \pm SEM and were analyzed with a student's t-test. n.s. = not significant. 
A

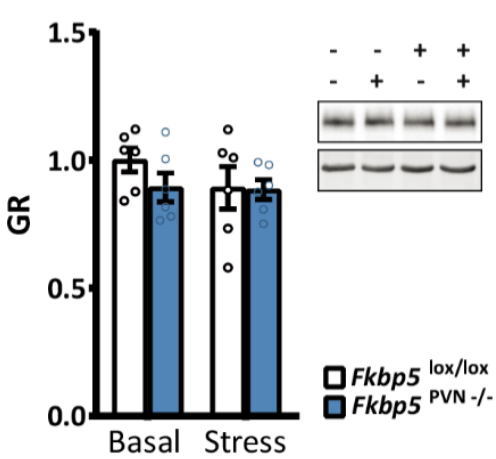

B

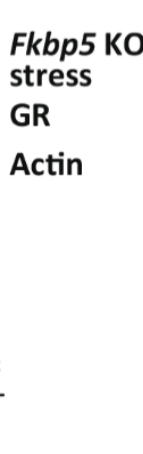

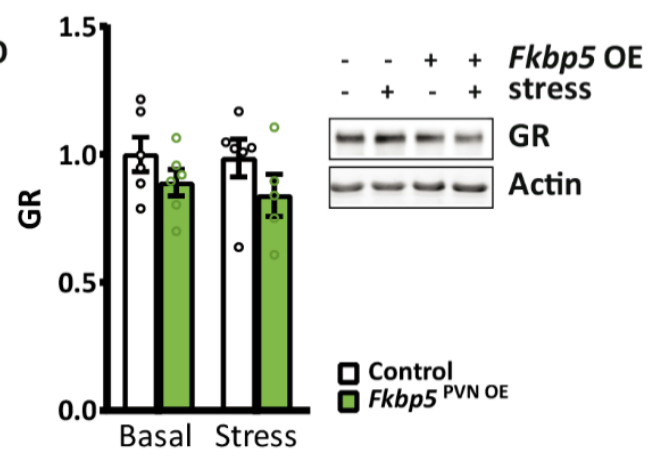

Suppl. Figure 5: PVN protein level of Fkbp5 and GR under basal and stressed conditions. (A) GR protein levels were unchanged in $F k b p 5^{\mathrm{PVN}-\digamma_{-}}$animals $(\mathrm{n}=6)$ and $(\mathrm{B})$ in $F k b p 5^{\mathrm{PVN} \mathrm{OE}}$ animals $(\mathrm{n}=6)$ under basal and stressed conditions. All data were analyzed with a two-way ANOVA.

\section{Supplementary Figure 6}

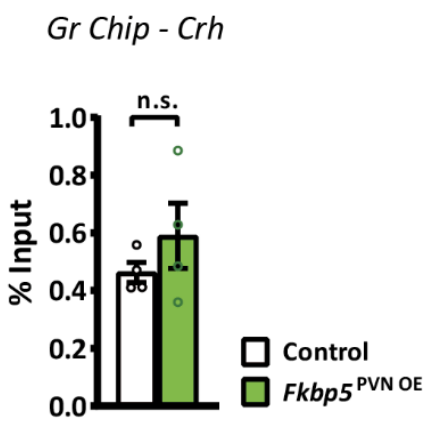

Suppl. Figure 6: GR to GRE binding within the $\mathrm{Crh}$ gene after stress. Mice were sacrificed 30 minutes after stress onset. Every $n$ consists of a pool of 4 individual hypothalami. All data are indicated as mean \pm SEM and were analyzed with a student's t-test; ( $n=4$ vs. 4 ); n.s. = not significant.

\section{Supplementary Figure 7}

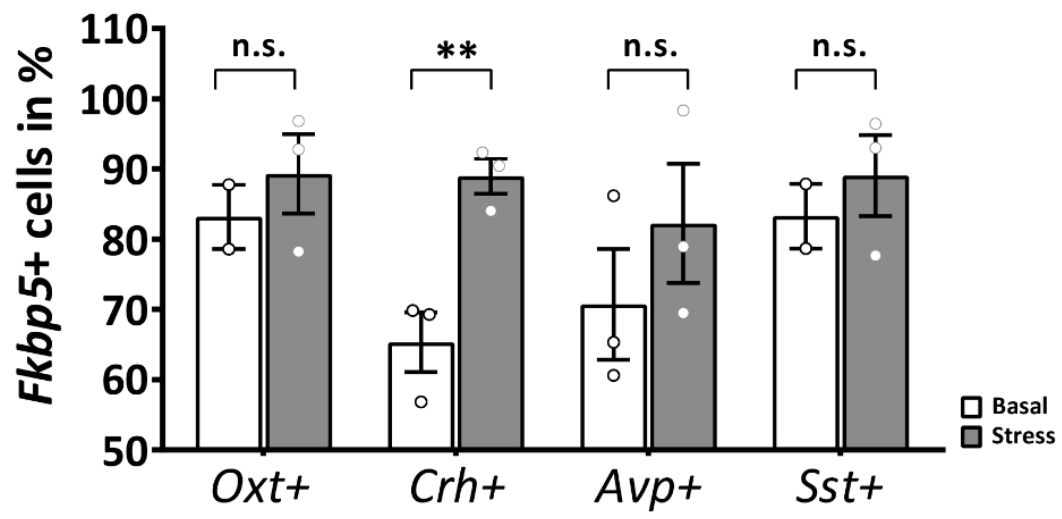

Suppl. Figure 7: Quantification of Fkbp5 co-localization in stress response markers under basal and stress conditions. Under basal conditions Fkbp5 mRNA signal was detected in $83 \%$ of Oxt+ neurons, $65 \%$ Of $C r h+$ neurons, $68 \%$ in Avp+ and $84 \%$ of $S s t+$ neurons. We monitored an increased in $F k b p 5$ mRNA expression in all neuronal populations. Interestingly, only $\mathrm{Crh}+$ neurons showed a significant increase of Fkbp5 mRNA following stress. All data are presented as mean \pm SEM and were analyzed with a student's t-test. ${ }^{* *}=p<0.01$. 